\title{
Importance of mineral cations and organics in gas-aerosol partitioning of reactive nitrogen compounds: case study based on MINOS results
}

\author{
S. Metzger $^{1}$, N. Mihalopoulos ${ }^{2}$, and J. Lelieveld ${ }^{1}$ \\ ${ }^{1}$ Max Planck Institute for Chemistry, Air Chemistry Department, Mainz, Germany \\ ${ }^{2}$ University of Crete, Department of Chemistry, Heraklion, Greece
}

Received: 4 October 2005 - Published in Atmos. Chem. Phys. Discuss.: 19 December 2005

Revised: 24 April 2006 - Accepted: 24 May 2006 - Published: 3 July 2006

\begin{abstract}
The partitioning of reactive nitrogen compounds between the gas and the aerosol phase, as observed during the MINOS (Mediterranean INtensive Oxidant Study) campaign in Crete, Greece, in July and August 2001, has been studied with three thermodynamic gas-aerosol equilibrium models (EQMs) of different chemical complexity: ISORROPIA, which is limited to the ammonium-sulfatenitrate-sodium-chloride-water-system; SCAPE2, which also includes mineral elements (calcium, magnesium and potassium); and EQSAM2, which additionally accounts for organic acids. The different EQMs are constrained by measured gas (g) and aerosol (a) concentrations: Total ammonia $\left(\mathrm{NH}_{3(g)}\right.$ and $\left.\mathrm{NH}_{4(a)}^{+}\right)$, total nitrate $\left(\mathrm{HNO}_{3(g)}\right.$ and $\left.\mathrm{NO}_{3(a)}^{-}\right)$, total sulfate $\left(\mathrm{H}_{2} \mathrm{SO}_{4(g)}\right.$ and $\left.\mathrm{SO}_{4(a)}^{2-}\right)$, total chloride $\left(\mathrm{HCl}_{(g)}\right.$ and $\left.\mathrm{Cl}_{(a)}^{-}\right)$, sodium $\left(\mathrm{Na}_{(a)}^{+}\right)$, calcium $\left(\mathrm{Ca}_{(a)}^{2+}\right)$, magnesium $\left(\mathrm{Mg}_{(a)}^{2+}\right)$, potassium $\left(\mathrm{K}_{(a)}^{+}\right)$and organic acids (a). Although the three EQMs differ considerably in particular aspects, their application at the same level of complexity yields comparable results for the equilibrium composition and phase partitioning of ammonia and nitric acid, i.e. within the range of measurement uncertainties $(\sim 10 \%)$. Their application at different levels of complexity, however, gives rise to substantial differences for the gas-aerosol partitioning of reactive nitrogen compounds. Our results show that only if (soluble) mineral components and (lumped) organic acids are accounted for, the observed gas-aerosol partitioning of ammonia and nitric acid can be accurately reproduced for air pollution episodes characterized by a complex chemical mixture, typical for the Mediterranean lower atmosphere.
\end{abstract}

Correspondence to: S. Metzger

(metzger@mpch-mainz.mpg.de)

\section{Introduction}

The MINOS (Mediterranean INtensive Oxidant Study) campaign (Lelieveld et al., 2002; Salisbury et al., 2003) took place in summer 2001 (28 July till 21 August) with the objective to study the chemical and transport processes that cause the relatively high pollution concentrations often encountered in the Eastern Mediterranean lower atmosphere (Fig. 1).

The measurements provided evidence of a remarkably high level of air pollution from the surface to the top of the troposphere up to $15 \mathrm{~km}$ altitude. Most pollution was observed in the lower $4 \mathrm{~km}$, originating from both western and eastern Europe (Lelieveld et al., 2002; Traub et al., 2003). During MINOS the observations at Finokalia were strongly influenced by the transport of air pollution from SE-Europe. The sources include industrial activity, traffic, forest fires, agricultural and domestic burning. Since the Mediterranean region is nearly cloud-free in summer, the solar radiation levels are high so that noxious reaction products are formed in photochemical smog. The consequent air pollution includes ozone, various aerosol precursor gases and acidic or hygroscopic aerosol particles with distinct chemical composition.

The most abundant aerosol precursor gases are ammonia $\left(\mathrm{NH}_{3}\right)$, sulfuric acid $\left(\mathrm{H}_{2} \mathrm{SO}_{4}\right)$ and nitric acid $\left(\mathrm{HNO}_{3}\right)$. While $\mathrm{NH}_{3}$ is an end product of biogenic activity, being emitted by farming and fertilization, $\mathrm{H}_{2} \mathrm{SO}_{4}$ and $\mathrm{HNO}_{3}$ are acids and oxidation products from gas-phase photochemistry. $\mathrm{H}_{2} \mathrm{SO}_{4}$ derives from sulfur dioxide $\left(\mathrm{SO}_{2}\right)$ and $\mathrm{HNO}_{3}$ from $\mathrm{NO}_{\mathrm{x}}$ $\left(\mathrm{NO}_{2}+\mathrm{NO}\right)$, i.e. trace gases released from combustion processes, e.g. in fossil energy production and traffic. Additional aerosol precursor gases include hydrochloric acid $(\mathrm{HCl})$ and various condensable organic acids (R-COOH). While sulfuric and nitric acid in the Mediterranean region mainly originate from anthropogenic activities, the origin of organic acids is manifold and less clear; a certain fraction originates from

Published by Copernicus GmbH on behalf of the European Geosciences Union. 


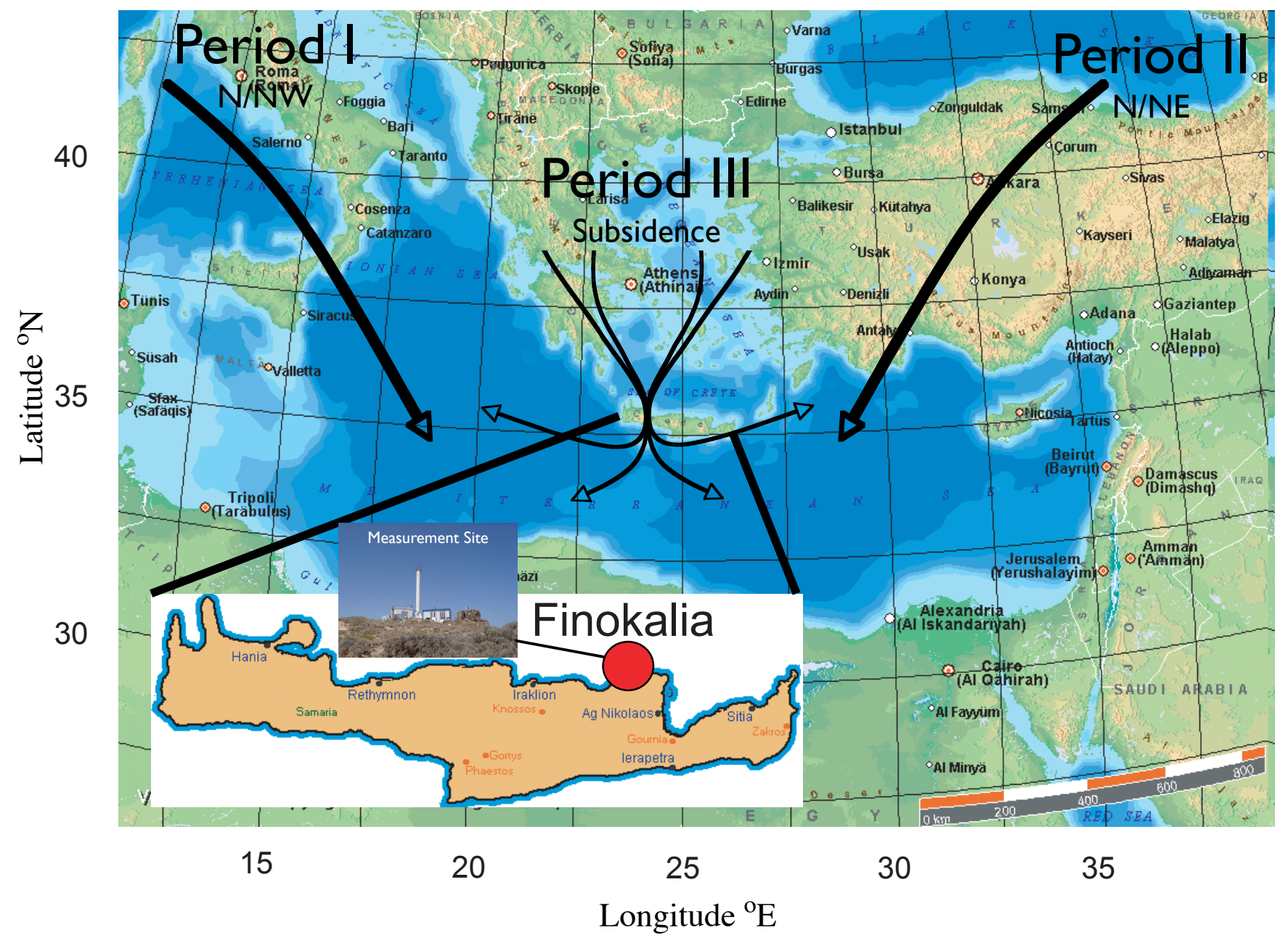

Fig. 1. Map of the eastern Mediterranean region, Crete and Finokalia station where the MINOS campaign was performed.

anthropogenic activity and, depending on the season, from natural sources such as forests and coastal ecosystems.

The corresponding ions are ammonium $\left(\mathrm{NH}_{4}^{+}\right)$, sulfate $\left(\mathrm{SO}_{4}^{2-}\right)$, bisulfate $\left(\mathrm{HSO}_{4}^{-}\right)$, nitrate $\left(\mathrm{NO}_{3}^{-}\right)$, chloride $\left(\mathrm{Cl}^{-}\right)$, and organics $\left(\mathrm{R}_{-} \mathrm{COO}^{-}\right)$. Except for $\mathrm{NH}_{4}^{+}$these are anions associated with gas-aerosol partitioning and the formation and growth of secondary aerosols (i.e. formed within the atmosphere), while the major cations are mainly of natural origin (primary aerosols), present in the coarse mode particles and not undergoing gas-aerosol partitioning (but liquid-solid partitioning). Most important are sodium $\left(\mathrm{Na}^{+}\right)$originating mainly from bubble bursting sea spray, calcium $\left(\mathrm{Ca}^{2+}\right)$, magnesium $\left(\mathrm{Mg}^{2+}\right)$ and a minor fraction of potassium $\left(\mathrm{K}^{+}\right)$ which originate from mineral dust, e.g. Saharan dust. The major mineral cations present in the fine mode largely originate from anthropogenic activity, including $\mathrm{NH}_{4}^{+}$, the cation of $\mathrm{NH}_{3}$, and "pyrogenic" potassium $\left(\mathrm{K}^{+}\right)$from biomass burning.
The anions are neutralized by cations through various reaction pathways, being important for several reasons. Firstly, trace gases with a short lifetime of a day or less can partition into aerosols, which subsequently have a much longer lifetime of about a week depending on size, composition and meteorological conditions. For instance, $\mathrm{NH}_{3}$ reacts with $\mathrm{H}_{2} \mathrm{SO}_{4}$ to form stable ammonium sulphate salts that are mostly confined to the aerosol fine mode. Secondly, the salts are more-or-less hygroscopic, so that the aerosols interact with natural and anthropogenic gases by heterogeneous reactions on aqueous or dry aerosol surfaces.

The present study addresses the influence of mineral cations and organic acids on the gas-aerosol partitioning of reactive nitrogen compounds in the Mediterranean lower atmosphere. We focus on nitrate and ammonium as they are the two dominant nitrogen-containing compounds in aerosol particles, mainly of anthropogenic origin.

While it has been demonstrated that nitrate is mainly present in the form of ammonium nitrate e.g. in northwestern 
and central Europe (e.g. Schaap et al., 2002), previous size fractionated aerosol measurements conducted in the Mediterranean have indicated the near-absence of submicron nitrate (Bardouki et al., 2003). The high hydroxyl (OH) levels occurring in the area during summer (up to about $2 \cdot 10^{7}$ molecules $/ \mathrm{cm}^{3}$ ), in conjunction with the relatively high $\mathrm{NO}_{\mathrm{x}}\left(\mathrm{NO}+\mathrm{NO}_{2}\right)$ concentrations and the lack of precipitation, promote the build-up of $\mathrm{HNO}_{3}$ from gas phase reactions (Berresheim et al., 2003). Once $\mathrm{HNO}_{3}$ is formed, it is most likely captured by coarse mode ( $\mathrm{D} \geq 1.2 \mu \mathrm{m})$ sea-salt and dust particles, leading to a depletion of aerosol nitrate in the fine mode $(\mathrm{D}<1.2 \mu \mathrm{m})$. On the other hand, when ammonia is present in excess ammonium nitrate can be formed during night; however, since this salt is thermodynamically not stable, it can evaporate during the day whereby the aerosol precursor gases $\mathrm{NH}_{3}$ and $\mathrm{HNO}_{3}$ are likely to condense on preexisting and larger aerosol particles (e.g. Wexler and Seinfeld, 1990). As a consequence, some anthropogenic air pollutants may not (or only during night) be confined to the fine aerosol mode but rather interact with larger particles which might be of natural origin such as sea salt and mineral dust aerosol.

To study the gas-aerosol partitioning of these compounds by considering inorganic and organic acids together with the major mineral cations that originate from sea salt and mineral dust (i.e. $\mathrm{Na}^{+}, \mathrm{Ca}^{2+}, \mathrm{Mg}^{2+}, \mathrm{K}^{+}$), we employ the available and widely used thermodynamic gas-aerosol equilibrium models ISORROPIA (Nenes et al., 1998), SCAPE2 (Kim et al., 1995; Meng et al., 1995) together with EQSAM2, which derives from EQSAM (Metzger, 2000; Metzger et al. 2002a,b). In contrast to ISORROPIA and SCAPE2, EQSAM2 includes both lumped organic acids and mineral cations; ISORROPIA is limited to the ammonium-sulfatenitrate-sodium-chloride-water-system, while SCAPE2 additionally includes major mineral cations $\left(\mathrm{Ca}^{2+}, \mathrm{Mg}^{2+}, \mathrm{K}^{+}\right)$. Compared to EQSAM, EQSAM2 also includes an extended description of gas-liquid-solid partitioning by accounting for the various mineral salt compounds based on theoretically derived activity coefficients and single solute molalities. A brief summary of the main new features of EQSAM2 is given in the Appendix. A detailed description, including theoretical aerosol thermodynamics considerations, is in preparation for a separate publication.

Note that all models are constrained by measured gas (g) and aerosol (a) concentrations, i.e. total ammonia $\left(\mathrm{NH}_{3(g)}\right.$ and $\left.\mathrm{NH}_{4(a)}^{+}\right)$, total nitrate $\left(\mathrm{HNO}_{3(g)}\right.$ and $\left.\mathrm{NO}_{3(a)}^{-}\right)$, total sulfate $\left(\mathrm{H}_{2} \mathrm{SO}_{4(g)}\right.$ and $\left.\mathrm{SO}_{4(a)}^{2-}\right)$, total chloride $\left(\mathrm{HCl}_{(g)}\right.$ and $\left.\mathrm{Cl}_{(a)}^{-}\right)$, sodium $\left(\mathrm{Na}_{(a)}^{+}\right)$, calcium $\left(\mathrm{Ca}_{(a)}^{2+}\right)$, magnesium $\left(\mathrm{Mg}_{(a)}^{2+}\right)$, potassium $\left(\mathrm{K}_{(a)}^{+}\right)$and organic acids (a), from which the phase partitioning between the gas/liquid, gas/solid and liquid/solid aerosol phase and the equilibrium composition is calculated by the models.

\section{Measurements}

\section{$2.1 \quad \mathrm{HNO}_{3}$ and $\mathrm{NH}_{3}$}

The technique used for the sampling of atmospheric $\mathrm{HNO}_{3}$ and $\mathrm{NH}_{3}$ is based on the nebulization/reflux principle (Cofer et al., 1985; Sciare and Mihalopoulos, 2000). The Cofer sampler was running with an average flow rate of $16 \mathrm{~L} \mathrm{~min}^{-1}$ and the sampling step was $2-3 \mathrm{~h}$. After sampling the aliquots for $\mathrm{HNO}_{3}$ and $\mathrm{NH}_{3}$ analysis were kept refrigerated at $4{ }^{\circ} \mathrm{C}$ in the dark and analyzed within a month period using Ion Chromatography (see details below). The detection limit for a mean sampling volume of $3 \mathrm{~m}^{3}$ was found to be $20 \mathrm{pmol} \mathrm{mol}^{-1}$ and the precision was estimated to be $15 \%$.

\subsection{Aerosol sampling and analysis}

Bulk aerosol samples were collected on $0.5 \mu \mathrm{m}$ PTFE filters running in parallel with the Cofer sampler. In total, 226 aerosol samples were collected during the sampling period and subsequently analyzed for the main anions and cations by Ion Chromatography. To obtain an impression of the distribution of aerosols over the fine and coarse mode, we also collected aerosol samples in parallel on Stack Filter Units (SFUs). The $50 \%$ cut-point diameter (D50) of the $8 \mu \mathrm{m}$ pore size filter was estimated to be of the order of $1.2 \pm 0.1 \mu \mathrm{m}$ E.A.D. More details can be found in Sciare et al. (2005).

For the analysis of anions (chloride: $\mathrm{Cl}^{-}$; bromide: $\mathrm{Br}^{-}$; nitrate: $\mathrm{NO}_{3}^{-}$; sulfate: $\mathrm{SO}_{4}^{2-}$; oxalate: $\mathrm{C}_{2} \mathrm{O}_{4}^{2-}$ ) a Dionex AS4A-SC column with ASRS-I suppressor in autosuppression mode of operation was used and isocratic elution at $2.0 \mathrm{ml} \mathrm{min}^{-1}$ of $\mathrm{Na}_{2} \mathrm{CO}_{3} / \mathrm{NaHCO}_{3}$ eluent. Organic anions were analyzed using a Dionex DX-500 Ion Chromatograph with an AS11 analytical column and $\mathrm{NaOH}(0.1-3.5 \mathrm{mM})$ as eluent in the gradient mode. For the cations (sodium: $\mathrm{Na}^{+}$; ammonium: $\mathrm{NH}_{4}^{+}$; potassium: $\mathrm{K}^{+}$; magnesium: $\mathrm{Mg}^{2+}$ and calcium: $\mathrm{Ca}^{2+}$ ) a CS12-SC column was used with CSRS-I suppressor. Separation was achieved under isocratic conditions with $20 \mathrm{mM}$ MSA eluent and flow rate of $1.0 \mathrm{ml} / \mathrm{min}$ : The reproducibility of the measurements was better than $2 \%$ and the detection limit ranged from around $5 \mathrm{ppb}$ for the main anions and cations to below $0.2 \mathrm{ppb}$ for the major organic anions. More details on the analytical technique can be found in Kouvarakis and Mihalopoulos (2002).

To support our modeling study, major low molecular weight (LMW) organic anions, being weak acids, were lumped together according their protonation constant, as they might be deprotonated in the presence of water (Reaction R1) and neutralized in case of excess cations, for instance sodium (Reaction R2), potassium (Reaction R3) or ammonium (Reaction R4).

$$
\begin{aligned}
\mathrm{R}-\mathrm{COOH}+\mathrm{H}_{2} \mathrm{O} & \Longleftrightarrow \mathrm{R}-\mathrm{COO}^{-}+\mathrm{H}_{3} \mathrm{O}^{+} \\
\mathrm{R}-\mathrm{COO}^{-}+\mathrm{Na}^{+} & \Longleftrightarrow \mathrm{R}-\mathrm{COONa} \\
\mathrm{R}-\mathrm{COO}^{-}+\mathrm{K}^{+} & \Longleftrightarrow \mathrm{R}-\mathrm{COOK}
\end{aligned}
$$




\section{EQSAM2 Aerosol Thermodynamics \\ Gas/liquid/solid partitioning}

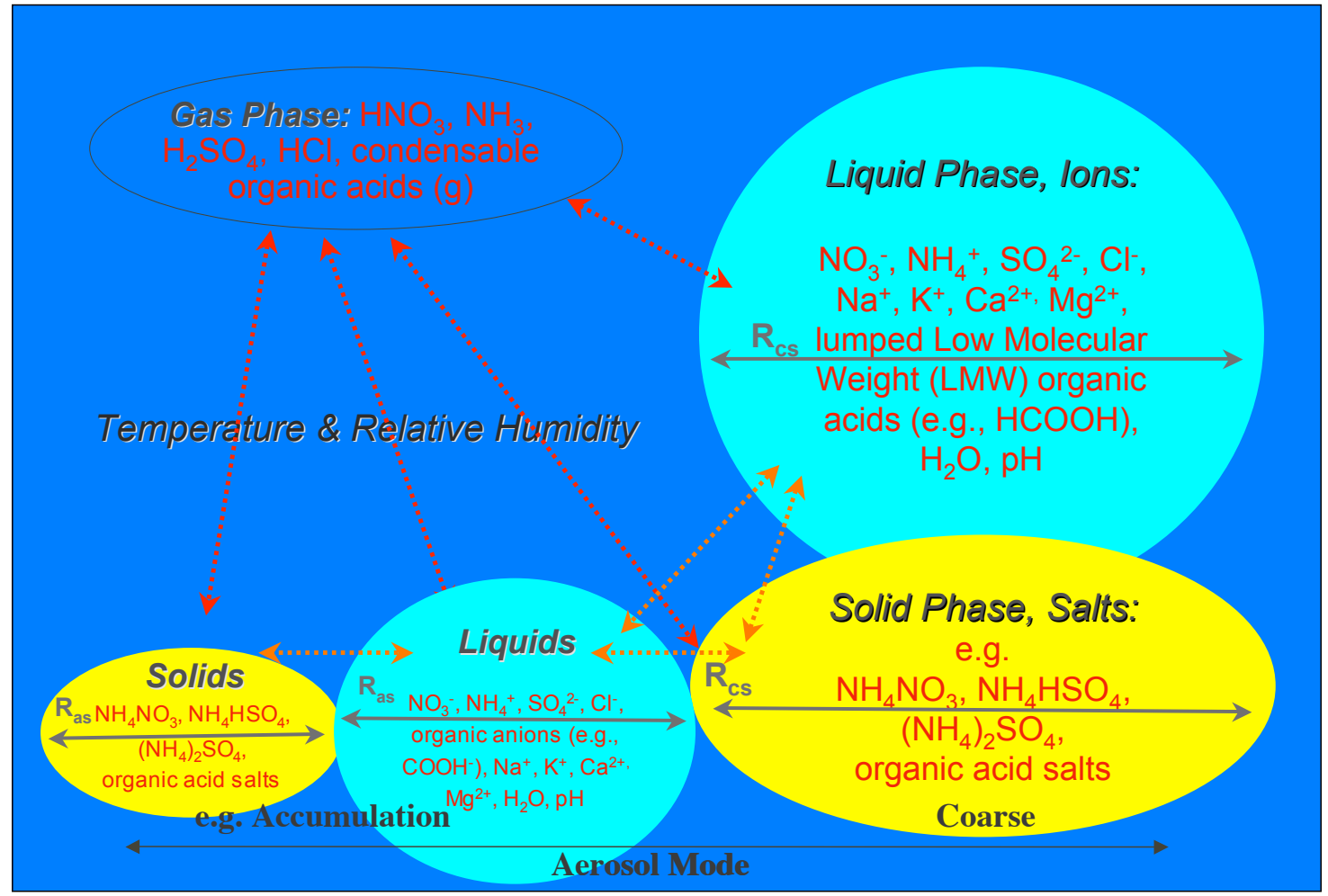

Fig. 2. Schematic description of the compounds and gas-aerosol partitioning processes included in EQSAM2.

$\mathrm{R}-\mathrm{COO}^{-}+\mathrm{NH}_{4}^{+} \Longleftrightarrow \mathrm{R}-\mathrm{COONH}_{4}$

Similar to the study by Trebs et al. (2005) equivalent moles were calculated as a first approximation assuming that mono, di-, and tricarboxylic acids form e.g. the respective mono-, di-, and tri-ammonium salts. By this we simply assume that the acids donate all $\mathrm{H}^{+}$to be neutralized by bases such as ammonia $\left(\mathrm{NH}_{3}\right)$, which forms the cation ammonium $\left(\mathrm{NH}_{4}^{+}\right)$. In addition we assume that the organic acids might be neutralized by the other cations $\left(\mathrm{Na}^{+}, \mathrm{Ca}^{2+}, \mathrm{Mg}^{2+}, \mathrm{K}^{+}\right)$. Although it is difficult to estimate the degree of acid dissociation (the $\mathrm{pH}$ of the sampled aerosol is not known), we assume that e.g. full acid dissociation of ammonium salts occurred, since excess of $\mathrm{NH}_{3}$ was available at the site. Organic acids are therefore added to the ionic charge balance accounting for the total of carboxylic groups.

During MINOS the following classes of organic acids were measured: monocarboxylic (formate, acetate and propionate), dicarboxylic (oxalate, succinate and glutarate) and ketocarboxylic (pyruvate). The above measured organic species account for the majority (more than $80 \%$ ) of the organic acids existing in the aerosol phase (Kawamura et al., 1996; Kawamura and Sakaguchi, 1999; Krivacsy et al., 2001) and concurrent measurements during the campaign
(A. Roemp et al., personal communication) confirm this conclusion. Note, however, that the total particulate organic matter (POM) was not measured and that the identified organic acids might only account for a small fraction of POM (approximately $10 \%$ according to Sect. 4.2.3).

\section{Model description}

The gas-aerosol partitioning of inorganic and organic aerosol compounds is modeled assuming thermodynamic and chemical equilibrium. To study the gas-aerosol partitioning we use the thermodynamic equilibrium models (EQMs) ISORROPIA (Nenes et al., 1998), SCAPE2 (Meng et al., 1995), which derives from SCAPE (Kim et al., 1995), and EQSAM2, an update of EQSAM (Metzger, 2000; Metzger et al., 2002a; see Appendix). The gas-aerosol equilibrium models are driven by observations and partition the major aerosol precursor gases and aerosol compounds between the gas-, liquid-, or solid aerosol phase based on the total of aerosol precursor gases and aerosol compounds. The gas-aerosol partitioning represented by EQSAM2 is schematically described in Fig. 2. The aerosol precursor gases are ammonia $\left(\mathrm{NH}_{3}\right)$, sulfuric acid $\left(\mathrm{H}_{2} \mathrm{SO}_{4}\right)$, nitric acid 
$\left(\mathrm{HNO}_{3}\right)$, hydrochloric acid $(\mathrm{HCl})$, and condensable organic acids (R-COOH), the latter being lumped together according to the total number of carboxylic groups. The corresponding ions are ammonium $\left(\mathrm{NH}_{4}^{+}\right)$, sulfate $\left(\mathrm{SO}_{4}^{2-}\right)$, bisulfate $\left(\mathrm{HSO}_{4}^{-}\right)$, nitrate $\left(\mathrm{NO}_{3}^{-}\right)$, chloride $\left(\mathrm{Cl}^{-}\right)$, and lumped organics $\left(\mathrm{R}_{-} \mathrm{COO}^{-}\right)$, respectively. For each aerosol species the aerosol precursor gases and anions are added (i.e. $\mathrm{NH}_{3}+\mathrm{NH}_{4}^{+}, \mathrm{H}_{2} \mathrm{SO}_{4}+\mathrm{SO}_{4}^{2-}+\mathrm{HSO}_{4}^{-}, \mathrm{HNO}_{3}+\mathrm{NO}_{3}^{-}, \mathrm{HCl}+\mathrm{Cl}^{-}$ , $\mathrm{R}-\mathrm{COOH}+\mathrm{R}-\mathrm{COO}^{-}$) and the total is used as input in the gas-aerosol models together with the total of the corresponding (major) cations, i.e. sodium $\left(\mathrm{Na}^{+}\right)$, calcium $\left(\mathrm{Ca}^{2+}\right)$, magnesium $\left(\mathrm{Mg}^{2+}\right)$ and potassium $\left(\mathrm{K}^{+}\right)$.

The gas-aerosol equilibrium models (re-)partition the anions based on stochiometric neutralization reactions with the cations, assuming chemical equilibrium, so that stronger acids drive the weaker acids out of the aerosol phase. For instance, chloride and nitrate anions are replaced by sulfate anions, since sulfuric acid is stronger than hydrochloric or nitric acid with respect to neutralization reactions. Chlorine release from the aerosol particles will follow the formation of nitrate. Organic acids are assumed to be weaker than the considered inorganic acids and are therefore driven out of the aerosol phase in case of insufficient cations. Similarly, ammonium is driven out of the aerosol phase (in the form of ammonia) in the presence of excess mineral cations. Since mineral cations originate mainly from primary production (e.g. wind blown dust or sea spray) they are therefore mainly present in the coarse rather than the fine aerosol particles. Thus cations strongly determine the particle size distribution, which in turn affects the gas-aerosol partitioning related to the ionic composition.

To take size distribution effects into account, we consider in this study simply a bi-modal aerosol size-spectrum with two major aerosol modes, i.e. the fine $(\mathrm{D}<1.2 \mu \mathrm{m})$ and coarse $(\mathrm{D} \geq 1.2 \mu \mathrm{m})$ mode. For each mode, we calculate the equilibrium composition from the total gas and aerosol concentrations. The gas-aerosol equilibrium partitioning is hereby based on size-segregated aerosol compounds that derive from the measured ion concentrations in the two modes.

The EQMs used calculate the gas-aerosol equilibrium partitioning based on the following assumptions. First of all, aerosol particles are assumed to be in thermodynamic and chemical equilibrium and internally mixed. While the latter assumption might be questionable under certain conditions, i.e. for coarse mode particles which originate from mineral dust (see discussion section), the equilibrium assumption is justified especially for fine particles. Smaller particles have shorter equilibrium time-scales than larger particles due to a larger surface to volume ratio. The equilibrium timescale is within the range of minutes to one hour for the conditions considered (Meng and Seinfeld, 1996), which is much shorter than the measurement intervals of about $2-3 \mathrm{~h}$. However, also the coarse particles can be regarded as internally mixed (and hence in equilibrium), if salt compounds are pre- dominant. For instance, sea salt particles are very hygroscopic (mainly due to the presence of $\mathrm{MgCl}_{2}$ ), so that the salt compounds deliquesce as soon as the relative humidity $(R H)$ exceeds the relative humidity of deliquescence $(R H D)$; e.g. for $\mathrm{MgCl}_{2}$ the $R H D$ is very low, i.e. $32 \%$ (at $298 \mathrm{~K}$ ). At $R H D$, the aerosol particle is then assumed to be a saturated solution of the inorganic salt compound(s) with the salts completely dissociated into the anion-cation pairs. By including the $R H D$ s of various mineral salt compounds including $\mathrm{MgCl}_{2}$, we can account for the fact that the air over sea is often foggy, even at a low $R H$, simply due to the presence of $\mathrm{MgCl}_{2}$ in sea salt aerosol particles. As a consequence, we can clearly distinguish maritime from continental, polluted and unpolluted air.

To optionally apply the composition models within 3-D regional air pollution or global climate models, a simplification is made with respect to the set of chemical reactions that needs to be solved. To reduce the computing time, the set of chemical reactions is minimized for a certain aerosol composition by dividing the entire concentration range into certain concentration domains (aerosol types) and sub-domains ( $R H D$ regimes), which match the actual aerosol composition (e.g. sulfate neutral, sulfate rich or very rich cases, etc.). This framework is common to all EQMs used, see Metzger et al. (2002a), and the references therein for details.

Furthermore, it is common to all EQMs used to calculate temperature (T) and $R H$ dependent gas-liquid-solid aerosol partitioning. This includes crystallization (or the deliquescence and dissociation into ions) of salt compounds, if the $R H$ drops (or exceeds) the $R H D$ of the salt compound or of the mixture of salts (then called MRHD - mutual relative humidity of deliquescence). The EQMs finally compute the aerosol composition for a certain $\mathrm{T}, R H$ and the total of the gas and aerosol concentrations, based on the gas-liquid-solid, or gas-liquid, or gas-solid partitioning (either of one depending on $\mathrm{T}, R H$ and the input concentrations), including the corresponding solid and/or ionic compositions, the aerosol associated water mass and other derived aerosol properties (e.g. $\mathrm{pH}$, or ionic strength of the solution) which are difficult to measure.

\section{Results}

The MINOS measurements taken at Finokalia, Crete, in the southern Aegean Sea (Fig. 1) were analyzed with the gasaerosol partitioning models for the MINOS core period, i.e. 1-18 August 2001. This core period can be subdivided into three different periods, i.e. two humid periods interrupted by a dry period:

- Period I (1 August-6 August 2001) was dominated by moderate winds from north-northwesterly direction, bringing humid air enriched with high levels of sea salt from central and western Europe over the Ionian Sea to Crete. 


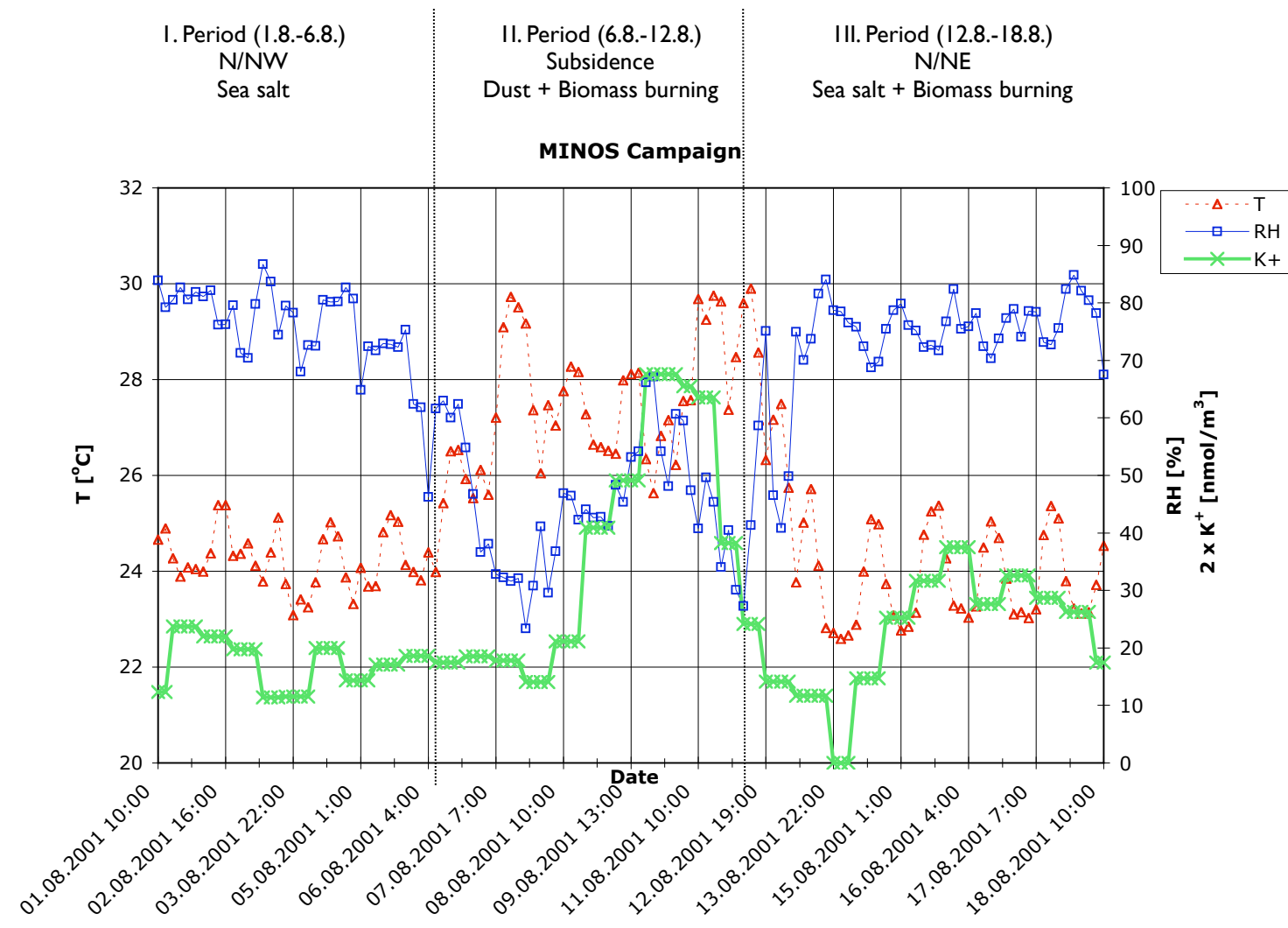

Fig. 3. Temperature (T), relative humidity $(R H)$ and potassium $\left(\mathrm{K}^{+}\right)$time evolution during the MINOS campaign for three different air pollution periods: Period I (1 August-6 August 2001) dominated by sea salt, period II (6 August-12 August 2001) dominated by mineral dust and biomass-burning air pollution, period III (12 August-18 August 2001) dominated by sea salt and biomass-burning air pollution. Note that potassium concentrations $\left[\mathrm{nmol} / \mathrm{m}^{3}\right]$, used as indicator for biomass burning, are scaled by a factor of two.

- Period II (6 August-12 August 2001) was dominated by subsidence, depositing pre-dominantly mineral dust from Saharan outbreaks, which was mixed or partly coated with biomass burning air pollution.

- Period III (12 August-18 August 2001) was dominated by moderate winds from north-northeasterly direction bringing again humid air with high levels of sea salt particles though in this case from eastern Europe over the Aegean Sea to Crete. Similarly to period II, the air was mixed with pollution from biomass burning.

\subsection{Observations}

For the three different periods that characterize the MINOS campaign, time evolutions of the air temperature $(\mathrm{T})$ and the relative humidity $(R H)$ are shown in Fig. 3, together with fine mode $(\mathrm{D}<1.2 \mu \mathrm{m})$ non-sea-salt potassium $\left(\mathrm{nss}-\mathrm{K}^{+}\right)$; the latter is conceived to be an indicator for biomass burning air pollution.

The three different periods can also be characterized by the pollution levels of atmospheric aerosols and their ionic composition. In particular, the concentration levels of cations are characteristic. Time averages for the three different periods, including the time averages over all periods of the observed aerosol and aerosol precursor gas concentrations in units of nanomole per cubic meter of air $\left(\mathrm{nmol} / \mathrm{m}^{3}\right)$ are shown for the fine and coarse mode in Fig. 4 (note the different scaling). The major mineral cations $\left(\mathrm{Na}^{+}\right.$from sea salt aerosols, $\mathrm{Ca}^{2+}, \mathrm{Mg}^{2+}$ ) are present in the coarse mode (more than $95 \%$ of the total concentration) which indicates their natural origin. The major mineral cation present in the fine mode is, besides $\mathrm{NH}_{4}^{+}$, pyrogenic potassium $\mathrm{K}^{+}$(more than $70 \%$ of the total concentration; Sciare et al., 2005).

The measurements further indicate that the major anthropogenic air pollutants are distributed over both the aerosol fine and coarse mode. For instance nss- $\mathrm{SO}_{4}^{2-}$ is mainly present in the aerosol fine mode in contrast to aerosol nitrate, which is confined to coarse mode particles. For a further discussion of the measurements, we refer to Salisbury et al. (2003), and Sciare et al. (2005). In the following we focus on the gas-aerosol partitioning modeling of reactive nitrogen compounds. 
a) Observation: Fine Mode $\left[\mathrm{nmol} / \mathrm{m}^{3}\right]$

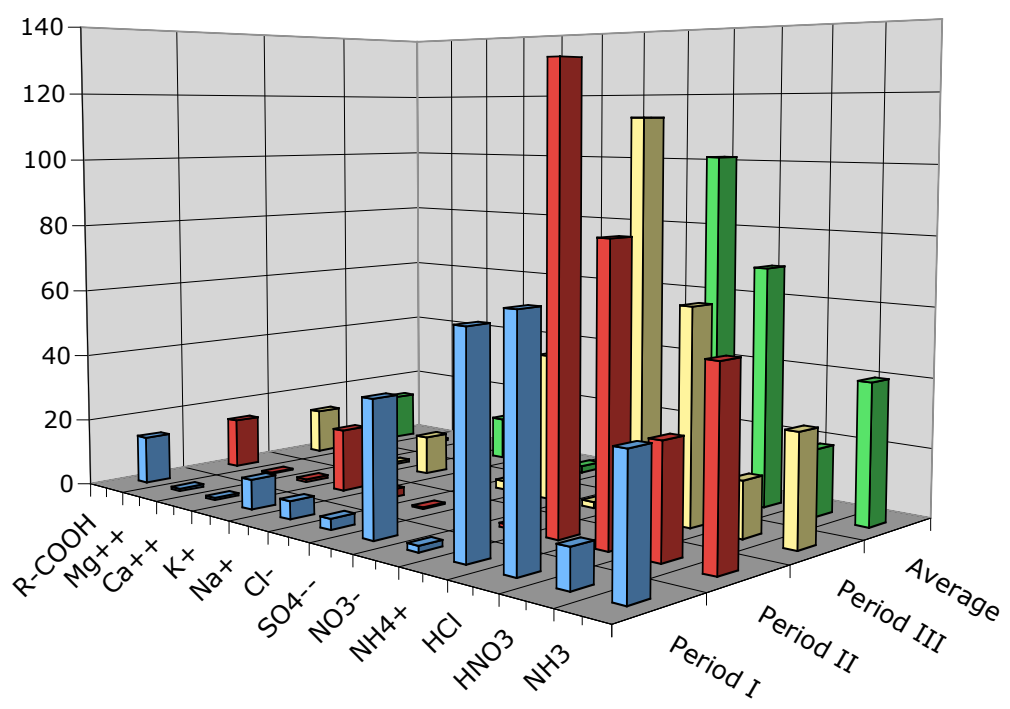

\begin{tabular}{|c|c|c|c|c|c|c|c|c|c|c|c|c|}
\hline & $\mathrm{NH3}$ & $\mathrm{HNO} 3$ & $\mathrm{HCl}$ & $\mathrm{NH} 4+$ & NO3- & SO4-- & $\mathrm{Cl}-$ & $\mathrm{Na}+$ & $\mathrm{K}+$ & $\mathrm{Ca}++$ & $\mathrm{Mg}++$ & $\mathrm{R}-\mathrm{COOH}$ \\
\hline Average & 40.50 & 19.45 & 69.73 & 101.24 & 1.58 & 42.75 & 2.07 & 4.09 & 12.83 & 0.71 & 0.57 & 14.14 \\
\hline Period III & 31.48 & 16.00 & 61.52 & 112.82 & 1.81 & 42.76 & 2.61 & 4.62 & 11.48 & 0.68 & 0.64 & 13.49 \\
\hline Period II & 53.78 & 31.77 & 81.93 & 128.87 & 1.10 & 47.03 & 0.40 & 2.37 & 18.39 & 0.78 & 0.33 & 14.92 \\
\hline Period I & 37.11 & 10.92 & 66.55 & 60.91 & 1.80 & 38.45 & 3.14 & 5.22 & 8.74 & 0.67 & 0.73 & 14.08 \\
\hline
\end{tabular}

b)

\section{Observation: Coarse Mode $\left[\mathrm{nmol} / \mathrm{m}^{3}\right]$}

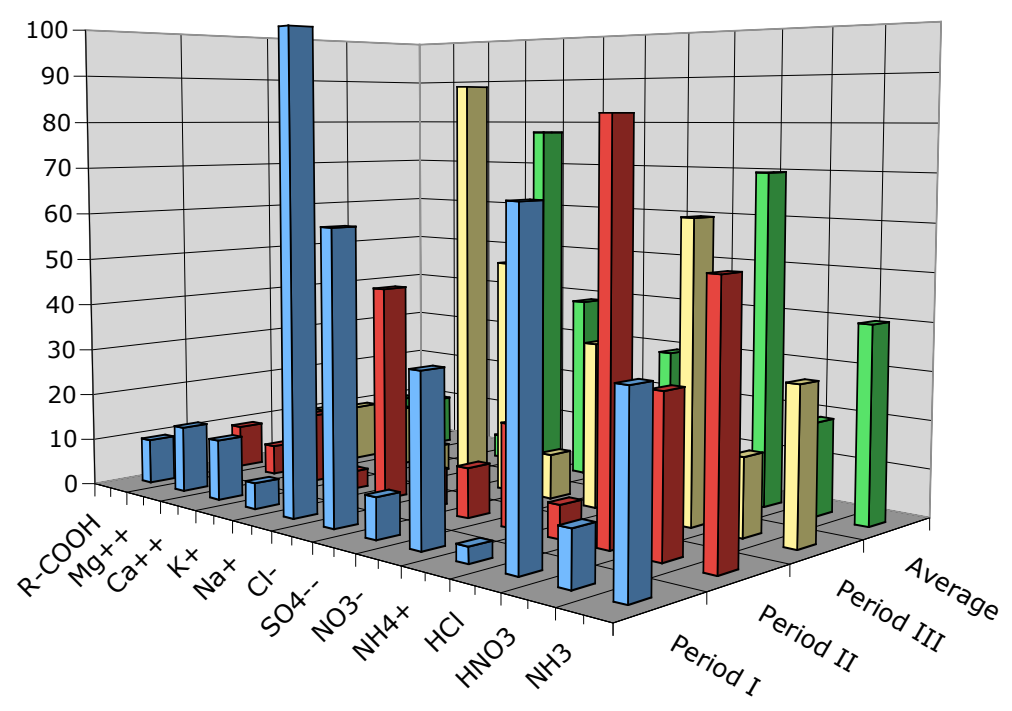

\begin{tabular}{|c|c|c|c|c|c|c|c|c|c|c|c|c|}
\hline & $\mathrm{NH} 3$ & $\mathrm{HNO} 3$ & $\mathrm{HCl}$ & $\mathrm{NH} 4+$ & NO3- & SO4-- & $\mathrm{Cl}-$ & $\mathrm{Na}+$ & $\mathrm{K}+$ & $\mathrm{Ca}++$ & $\mathrm{Mg}++$ & R-COOH \\
\hline Average & 40.50 & 19.45 & 9.73 & 5.33 & 29.96 & 9.38 & 39.28 & 77.64 & 5.05 & 13.46 & 10.86 & 9.55 \\
\hline Period III & 31.48 & 16.00 & 61.52 & 5.94 & 34.34 & 9.39 & 49.56 & 87.82 & 5.85 & 12.91 & 12.24 & 9.98 \\
\hline Period II & 53.78 & 31.77 & 81.93 & 6.78 & 20.84 & 10.32 & 7.62 & 44.96 & 3.80 & 14.80 & 6.29 & 9.13 \\
\hline Period I & 37.11 & 10.92 & 66.55 & 3.21 & 34.27 & 8.44 & 59.67 & 99.15 & 5.43 & 12.73 & 13.90 & 9.49 \\
\hline
\end{tabular}

Fig. 4. Time averages of observed aerosol precursor gas and aerosol concentrations $\left[\mathrm{nmol} / \mathrm{m}^{3}\right]$ for the three different periods as defined in Fig. 3. Panel (a) shows the aerosol fine mode, and panel (b) the coarse mode aerosol. 
Table 1. Aerosol chemical systems considered in the different equilibrium models.

\begin{tabular}{cccl}
\hline Fine & Coarse & Model & Aerosol system \\
\hline F1 & $\mathrm{C} 1$ & $1,2,3$ & $\mathrm{H}_{2} \mathrm{SO}_{4} / \mathrm{HSO}_{4}{ }^{-} / \mathrm{SO}_{4}{ }^{2-}-\mathrm{HNO}_{3} / \mathrm{NO}_{3}{ }^{-}-\mathrm{NH}_{3} / \mathrm{NH}_{4}{ }^{+}-\mathrm{H}_{2} \mathrm{O}$ \\
$\mathrm{F} 2$ & $\mathrm{C} 2$ & $1,2,3$ & $\mathrm{~F} 1 / \mathrm{C} 1+\mathrm{HCl} / \mathrm{Cl}^{-}-\mathrm{Na}^{+}$ \\
F3 & $\mathrm{C} 3$ & $1,2,3$ & $\mathrm{~F} 2 / \mathrm{C} 2+\left(\mathrm{Ca}^{2+}+\mathrm{Mg}^{2+}+\mathrm{K}^{+}\right)$as equivalent $\mathrm{Na}^{+}$ \\
F4 & $\mathrm{C} 4$ & 1,2 & $\mathrm{~F} 2 / \mathrm{C} 2+\mathrm{Ca}^{2+}+\mathrm{Mg}^{2+} \mathrm{K}^{+}$ \\
F5 & $\mathrm{C} 5$ & 1 & $\mathrm{~F} 4 / \mathrm{C} 4+$ organic acids \\
\hline$* 1=$ EQSAM2 $2=$ SCAPE2, $3=$ ISORROPIA
\end{tabular}

\subsection{Modeling}

To study the $\mathrm{T}$ and $R H$ dependent equilibrium partitioning of reactive nitrogen compounds of the observed $\mathrm{H}_{2} \mathrm{SO}_{4} / \mathrm{HSO}_{4}^{-} / \mathrm{SO}_{4}^{2-}-\mathrm{HNO}_{3} / \mathrm{NO}_{3}^{-}-\mathrm{NH}_{3} / \mathrm{NH}_{4}^{+}-\mathrm{HCl} / \mathrm{Cl}^{-}-$ $\mathrm{Na}^{+}-\mathrm{Ca}^{2+}-\mathrm{Mg}^{2+}-\mathrm{K}^{+}-\mathrm{H}_{2} \mathrm{O}$-system, including lumped organic acids $(\mathrm{R}-\mathrm{COOH})$, we separate this complex aerosol system into five chemical systems for the fine (F1-F5) and the coarse (C1-C5) aerosol mode, according to Table 1. Chemical system F1/C1 excludes all mineral cations, F2/C2 accounts for sodium, F3/C3 for $\mathrm{Ca}^{2+}, \mathrm{Mg}^{2+}, \mathrm{K}^{+}$ as equivalent sodium, F4/C4 accounts explicitly for all mineral cations (SCAPE2 and EQSAM2 only) and F5/C5 also accounts for additional anions from lumped organic acids (EQSAM2 only).

This distinction allows investigating the gas-aerosol partitioning of nitrogen compounds and the sensitivity to the choice of the aerosol chemical subsystem. This is achieved by different constraints on the ionic composition, i.e. by subsequently including more and more cations and anions. This separation further allows comparing the results of differently complex equilibrium models (ISORROPIA, SCAPE2, EQSAM2) at different levels of complexity. While the models are only comparable if applied at the same level of complexity, i.e. for the aerosol chemical systems F1/C1 and $\mathrm{F} 2 / \mathrm{C} 2$, and with some restrictions also for $\mathrm{F} 3 / \mathrm{C} 3$, the model comparison at different levels of complexity (F4/C4 and F5/C5) focuses on the relative importance of individual aerosol components for the gas-aerosol partitioning of nitrogen compounds.

The most complex chemical system (F5/C5) is given by including all measurements. However, only EQSAM2 matches the chemical system F5/C5, while SCAPE2 is restricted to chemical system F4/C4 and ISORROPIA to F2/C2. Nevertheless, mineral cations can be considered by all three models, if mineral cations are added as " $\mathrm{Na}^{+}$-equivalent" to the sodium (e.g. 1 mole of $\mathrm{Mg}^{2+}$ as 2 mole $\mathrm{Na}^{+}$). This so-called equivalent sodium approach (Moya et al., 2001) yields chemical system F3/C3 (Table 1), which should be considered however as an approximation only, because of inconsistencies in the RHDs (see discussion section).

Note that all EQMs use as input for all cases the total of the measured gas and size-segregated aerosol phase concentrations of the considered species. The selection of species included in the calculations depends on the defined cases and size fractions, e.g. F1 or $\mathrm{C} 1, \mathrm{~F} 2$ or $\mathrm{C} 2$, etc. For each case (and size fraction) gas/liquid/solid phase partitioning and the composition of the size-segregated aerosols is calculated depending on observational data, which include temperature and relative humidity. The predicted size-segregated chemical composition is then compared with observations. Ideally, the models should be able to predict the observations if all major aerosol species have been measured and used for the calculations. But even if a model fails, for instance, due to the limited chemical complexity (e.g. of organic acids), the results are of interest as the failure might point to a potential relevance of the missing aerosol species.

\subsubsection{Gas-liquid-solid partitioning}

To study the gas-aerosol partitioning of size-fractionated nitrogen compounds, we first investigate in this section the relative importance of the choice of the chemical system and of the modeling approach (application of different EQMs). Since ammonia is the relatively weakest base, its cation ammonium is driven out of the aerosol phase in the presence of sufficient mineral cations. Ammonium is hence an ideal indicator for a sensitivity study of the gas-aerosol partitioning of size-fractionated nitrogen compounds. We therefore first address the ammonium partitioning, defined as the concentration ratio of ammonium to the total of ammonia and ammonium (Fig. 5). It is calculated from time averages (over all periods) of observed and predicted ammonia and ammonium concentration for fine and coarse mode particles and for all chemical systems (Table 1). Note that the partitioning is expressed in percent, which can result in large values pertaining to small concentrations, thus highlighting small differences, which underscores discrepancies between 


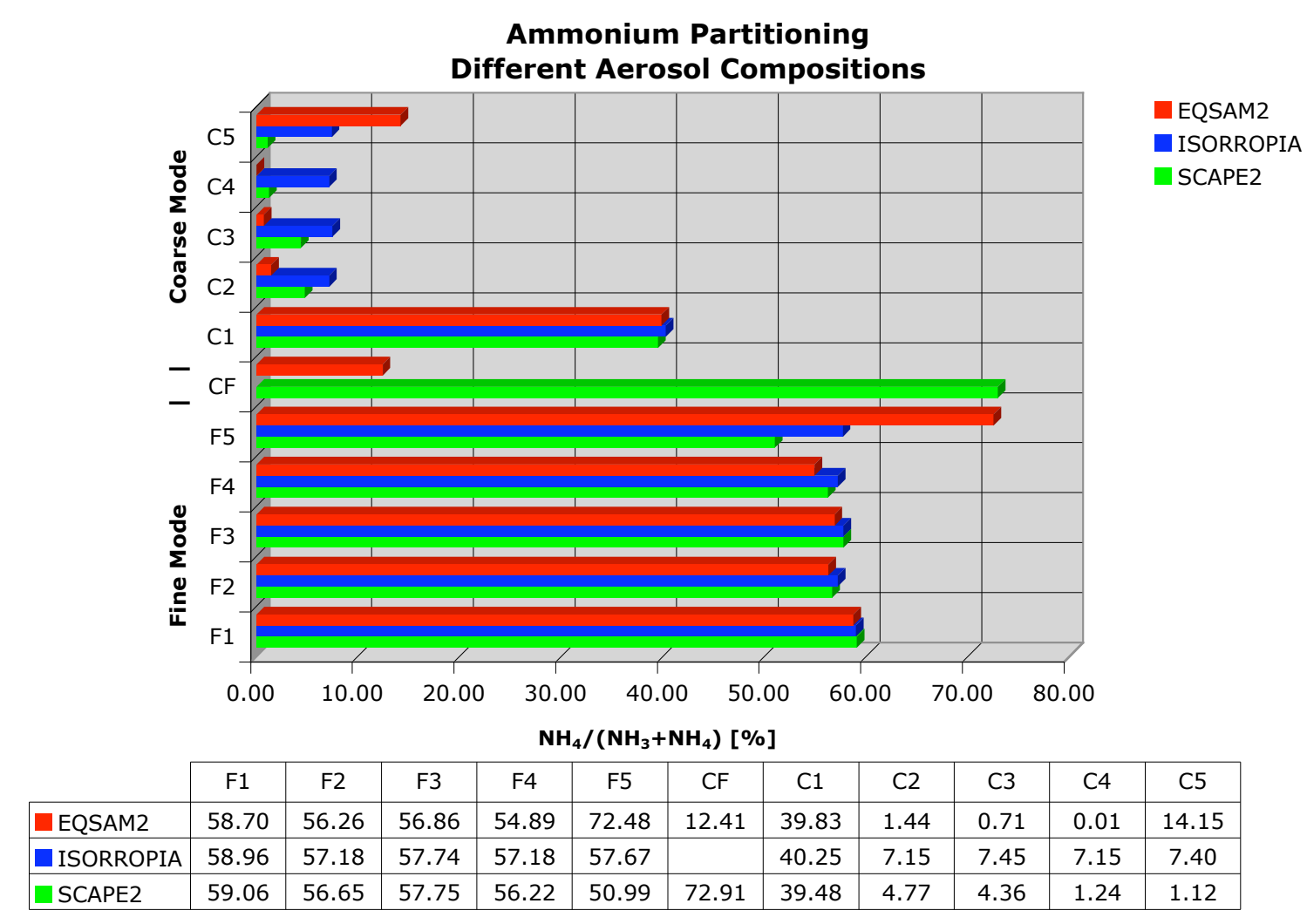

Fig. 5. Time averages (entire measurement time period) of observed and model calculated ammonium partitioning (ratio of aerosol ammonium and ammonium plus ammonia) [\%] for the fine (F) and coarse (C) aerosol mode and for all aerosol systems (F1-F5 and C1-C5) given in Table 1. For each system, all three model predictions are shown: from top to bottom EQSAM2 (red), ISORROPIA (blue) and SCAPE2 (green), whereas the observations (CF) are shown in the middle between the two aerosol modes starting from top to bottom with the coarse $(\mathrm{C}$, red) and fine $(\mathrm{F}$, green) modes.

models and observations. Note further that Fig. 5 also allows a comparison of the different model predictions of the three EQMs (ISORROPIA, SCAPE2, EQSAM2) with each other and with the observations for both the coarse and fine modes.

The observations (marked as CF in Fig. 5) show that on average $73 \%$ of the ammonium partitioned into the fine mode (F), while only about $13 \%$ partitioned into the coarse mode (C). The EQMs underestimate the fraction of fine mode ammonium for all chemical systems except F5 (EQSAM2) and $\mathrm{C} 1$ (all EQMs). This underestimation increases as more mineral cations $\left(\mathrm{Na}^{+}, \mathrm{Ca}^{2+}, \mathrm{Mg}^{2+}, \mathrm{K}^{+}\right)$are considered $(\mathrm{F} 1-$ $\mathrm{F} 4$ and $\mathrm{C} 1-\mathrm{C} 4)$. The increasing underestimation of the ammonium partitioning is most pronounced for SCAPE2 and EQSAM2 (except F5/C5) as both explicitly include all mineral cations; for ISORROPIA the values are approximately constant for F2-F5 and C2-C5, since mineral cations except sodium $\left(\mathrm{Na}^{+}\right)$are not explicitly accounted for in the model framework in contrast to SCAPE2 and EQSAM2 (see note at end of this section).

On the other hand, if all mineral cations $\left(\mathrm{Na}^{+}, \mathrm{Ca}^{2+}\right.$, $\mathrm{Mg}^{2+}, \mathrm{K}^{+}$) are omitted, i.e. chemical system $\mathrm{C} 1$, all EQMs largely overestimate the amount of ammonium partitioned into the coarse mode. In this case, the large amount of ammo- nium in the coarse fraction (C1) is only a result of the modeling constraint. Because no coarse mode mineral cations were allowed to be present in this $\mathrm{C} 1$ case, ammonium was the only cation to neutralize the anions. This results in unrealistically high concentrations of coarse ammonium calculated by all models as compared to observations. And since all three models agree for this artificial case within $1 \%$, we do have a clear indication that mineral cations (which preferentially neutralize the anions) must have been present in reality, resulting in the observed ammonia gas and ammonium aerosol phase concentrations.

Interestingly, this is not the case for the same chemical system if it is applied to the fine mode (F1). Obviously, insufficient anions of the ammonium-sulfate-nitrate-water-system are available for neutralization by ammonia to get a sufficient amount of ammonium into the fine aerosol phase (F1). Only if the additional anions from (lumped) organic acids are taken into account in the EQSAM2 model, ammonium realistically partitions into the aerosol phase. As a result, the predicted average ammonium partitioning is comparable to the observations within $1-2 \%$ for both the aerosol fine and coarse mode (F5/C5). 
a)

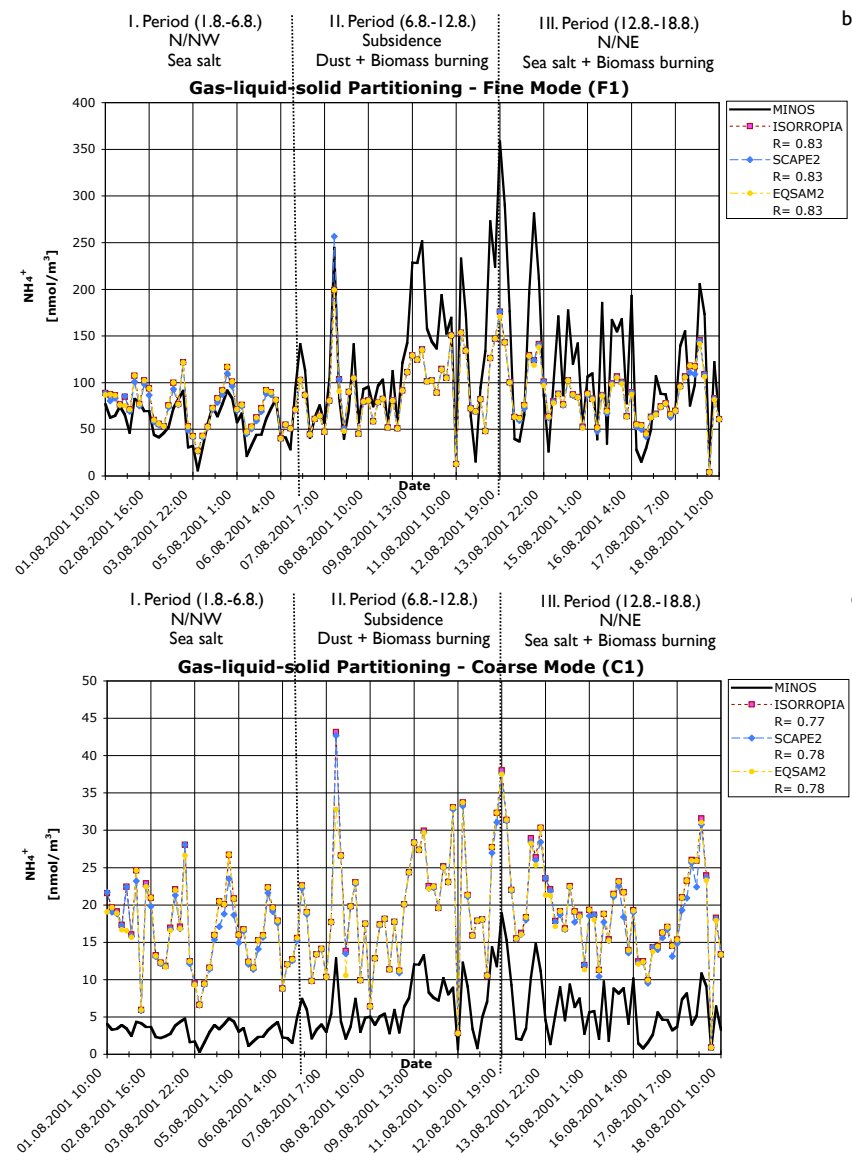

b)
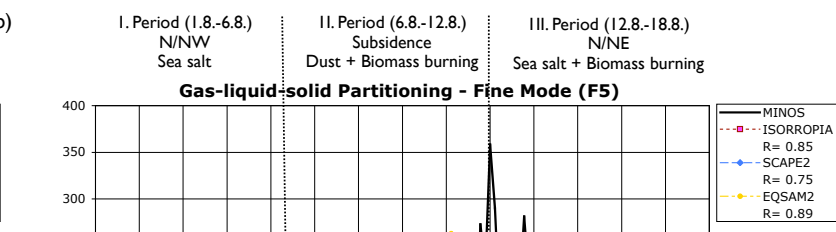

+

d)

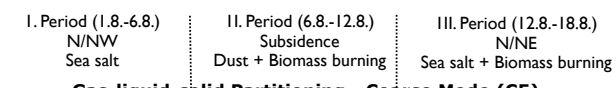

Gas-liquid-solid Partitioning - Coarse Mode (C5)

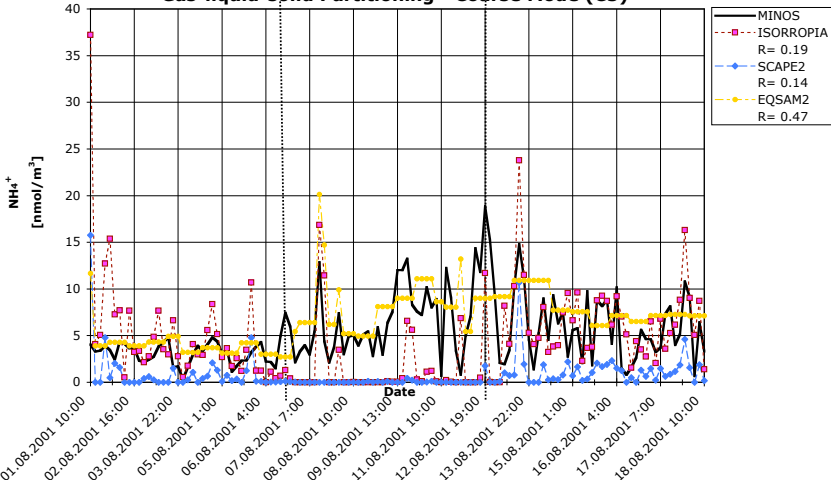

Fig. 6. Time series of measured (black solid line) fine mode aerosol ammonium (panels a and b) [nmol/ $\left.\mathrm{m}^{3}\right]$ and coarse (panels $\mathbf{c}$ and $\mathbf{d}$ ) mode ammonium $\left[\mathrm{nmol} / \mathrm{m}^{3}\right.$ ] for two different aerosol systems: The reduced chemical system (panels a and c) neglecting all cations except ammonium (F1/C1) and the most complete chemical system (F5/C5) (panels b and d) including mineral cations $\left(\mathrm{Na}^{+}, \mathrm{K}^{+}, \mathrm{Ca}^{2+}, \mathrm{Mg}^{2+}\right.$ ). For each model the correlation coefficient $(\mathrm{R})$ is given. The model results are obtained with ISORROPIA (purple, dashed line with closed squares), SCAPE2 (blue, long dashed line with closed diamonds), EQSAM2 (gold, short-long dashed line with closed circles).

It should be noted that all three EQMs give, within the measurement uncertainty of approximately $10 \%$, comparable results for the ammonium partitioning if applied at the same level of complexity, i.e. for the chemical systems F1/C1 and $\mathrm{F} 2 / \mathrm{C} 2$, and with the above-mentioned restrictions also for $\mathrm{F} 3 / \mathrm{C} 3$. However, the model comparison at higher levels of complexity (F4/C4 and F5/C5) indicates that it is important for the gas-aerosol partitioning of nitrogen compounds to consistently include mineral cations and organic acids, since the model predictions are only comparable to the observations if both, mineral cations and organic acids are considered (F5/C5).

Note further that for ISORROPIA the results are the same for the cases F4/C4 and F2/C2 as the model complexity is the same. However, F3/C3 differs due to the equivalent sodium approach, while the results differ for F5/C5 due to differences in the concentrations of mineral cations as discussed below (missing insoluble fraction). For the same reason, the results of SCAPE2 differ (from F4/C4 to F5/C5) although the level of model complexity is the same.

\subsubsection{Aerosol system F1/C1 compared to F5/C5}

In this section we investigate the time evolution of the gasaerosol partitioning of size-fractionated ammonium compounds over the three different periods (Period I-III). Similar to the previous section, we focus on the ammonium partitioning. Figure 6 shows the time series of the observed ammonium concentrations (in $\mathrm{nmol} / \mathrm{m}^{3}$ air) for the aerosol fine and coarse mode, together with the model predictions by ISORROPIA, SCAPE2 and EQSAM2 for the chemical systems F1/C1 and F5/C5 (Table 1), which exclude and include mineral cations $\left(\mathrm{Na}^{+}, \mathrm{Ca}^{2+}, \mathrm{Mg}^{2+}, \mathrm{K}^{+}\right)$and organic acids, respectively.

Firstly, Figs. 6a and c confirms that all three EQMs are in an excellent agreement if applied at the same level of complexity (F1/C1). However, they fail to predict the observed fine and coarse mode concentrations of ammonium for all three periods. The only exception is the relatively realistic partitioning of fine mode ammonium for period I. Since all three EQMs also give similar results for system F5 and 
period I, it indicates that mineral cations and organic acids are unimportant for the ammonium partitioning for period I (fine aerosol mode). Obviously, for this period the fine mode is well represented by chemical system F1 since sulfate is the predominant anion, being predominantly neutralized by ammonium as a result of the limited availability of mineral cations (Fig. 4a).

For periods II and III the situation considerably differs as both are affected by biomass burning, as indicated by enhanced concentrations of potassium in the aerosol fine mode. As a result, ammonium is driven out of the aerosol phase by the additional potassium cations, which preferentially neutralize the inorganic anions. Only if additionally organic anions are considered in EQSAM2, the model reproduces measured ammonium concentrations in the fine mode. This is only accomplished by the model predictions of EQSAM2 (chemical system F5, Fig. 6b). Since both minerals and organic acids (together) are not accounted for in the other two EQMs, the results do not improve. Instead, the results become worse for SCAPE2 as this model only considers additional cations $\left(\mathrm{Ca}^{2+}, \mathrm{Mg}^{2+}, \mathrm{K}^{+}\right)$but no organic acids, with the result that even more ammonium is driven out of the aerosol phase. In contrast, the results of ISORROPIA do not change, as these additional cations are not considered.

In strong contrast to the fine mode (Fig. 6a), all EQMs largely overestimate the ammonium concentrations for the coarse mode (Figs. 6c and d), if the calculations do not take into account mineral cations (chemical system C1, Fig. 6c). Mineral cations are predominant in the coarse mode for all periods (Fig. 4b). A further consequence of this is that SCAPE2 and ISORROPIA hardly predict any coarse mode ammonium for period II (Fig. 6d). The reason is that the sea salt concentrations are relatively low and the concentrations of cations from mineral (Saharan) dust high. While the predictions of SCAPE2 fail more-or-less for all periods as a result of the fact that mineral cations have been considered, the predictions of ISORROPIA particularly fail for the relatively dry period II as a consequence of the overall lower total anion (and in particular chloride) concentrations (see table below Fig. 4b). However, for the two humid periods with high sea salt concentrations (period I and III) the coarse mode simulations with ISORROPIA compare relatively well for the wrong reason, i.e. only because both mineral cations and lumped organic acids are neglected in the modeling approach. As demonstrated with the EQSAM2 calculations, both seem to be important for the gas-aerosol partitioning of reactive nitrogen compounds for certain Mediterranean conditions (period II and III).

4.2.3 Sensitivity to organic acids and mineral cations (F5/C5)

In this section we focus on the sensitivity of the gas-aerosol partitioning of reactive nitrogen compounds to the concentrations of organic acids and mineral cations. We first focus on the ammonium concentrations, for which we discuss only the fine mode. Ammonium is predominantly present in the fine mode and in competition with pyrogenic potassium, which is the predominant mineral cation in the fine mode as shown above (Fig. 4a).

To account for a potential disequilibrium for coarse mode particles due to the longer equilibration timescales of larger particles (smaller surface to volume ratio) or the unknown amount of insoluble matter (especially of mineral dust particles), we also study the sensitivity of coarse mode nitrate to the insoluble fraction of mineral cations from coarse mode sea salt and mineral dust.

\section{Organic acids (F5)}

Figure $7 \mathrm{a}$ shows similar to Fig. $6 \mathrm{~b}$ time series of the measured ammonium concentrations (in $\mathrm{nmol} / \mathrm{m}^{3}$ air) for the aerosol fine mode (chemical system F5), together with the model results with ISORROPIA, SCAPE2 and EQSAM2, while Fig. 7b shows the associated scatter plots (model versus observations). In addition, the results of EQSAM2* are shown. The asterisk $(*)$ denotes that EQSAM2 was constrained with different input concentrations (see below).

In contrast to EQSAM2 (see discussion of Fig. 6b), the predicted concentrations of fine mode ammonium by EQSAM2* are, according to Figs. 7a and b, much closer to the results of ISORROPIA and SCAPE2 for period II and III, only due to differences in the input concentrations of lumped organic acids, which were lower during all periods for EQSAM2* (discussion follows). In particular the high ammonium concentrations, which are confined to the biomass burning periods (II-III), are only reproduced by EQSAM2. Note that the correlation coefficients $(\mathrm{R})$ given in the legends need not necessarily to be in agreement with the scatter shown in Fig. 7b. The reason is that the correlation coefficient is mainly phase sensitive (i.e. $\mathrm{R}=1$ means that the values occur at the same time), while the scatter (slope) shows the error in amplitude (i.e. a zero error or one-by-one slope if the predicted values are identical to the observed values at a certain time).

Obviously, there is a threshold value for the input concentration of lumped organic acids at which the ammonium is predicted in the aerosol phase in amounts as observed. This threshold value can be determined by the difference between total anions and cations, by accounting for the observed ammonium concentrations. For instance, for this study the required input concentration (threshold value) of the lumped organic acids - needed to balance the aerosol ammonium with respect to the observed concentration - has been estimated to best match the observed ammonium concentration for each period, by running EQSAM2 twice. In the first run the model is constrained by observed ammonia and ammonium concentrations to predict the amount of (lumped) organic acids that are required to balance the model predictions for aerosol ammonium with the observations (inverse 
a)

I. Period (1.8.-6.8.)
N/NW
Sea salt
II. Period (6.8.-12.8.) Subsidence
Dust + Biomass burning
III. Period (12.8.-18.8.)
N/NE

Sea salt + Biomass burning

Aerosol Ammonium Gas-liquid-solid Partitioning - Fìne Mode (F5)

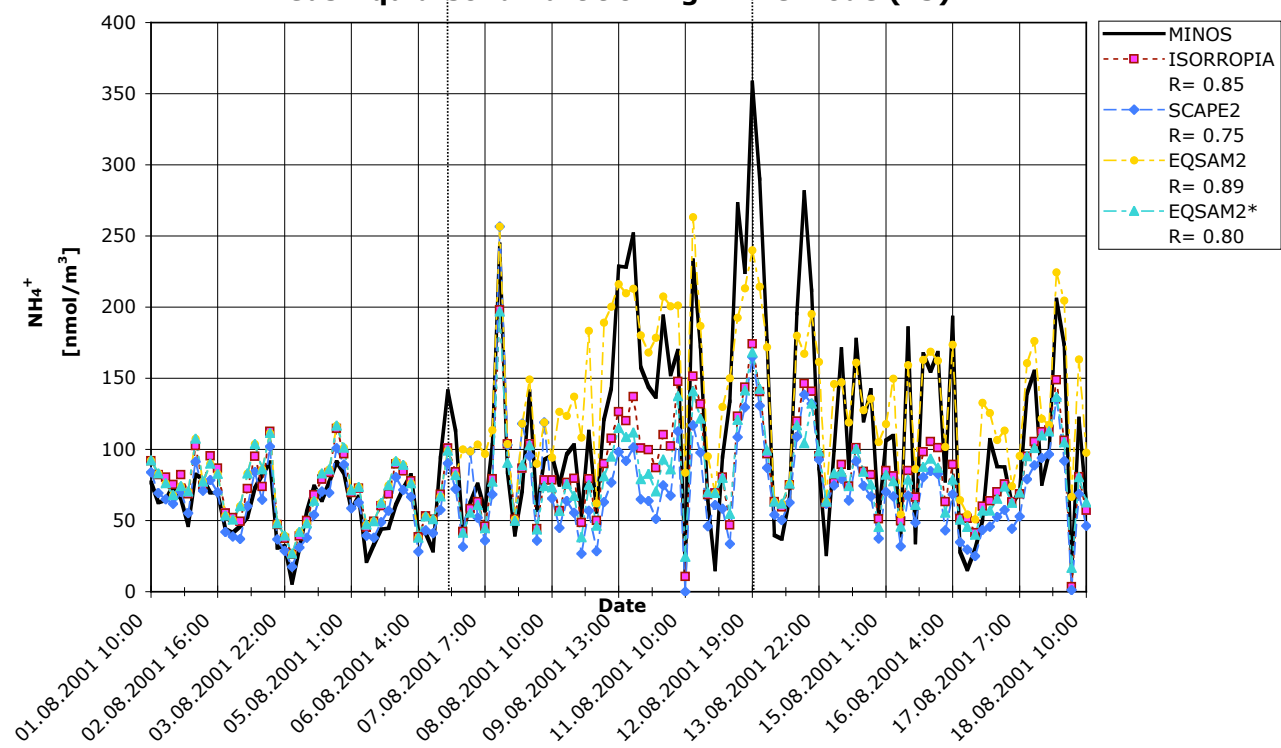

b)

Aerosol Ammonium

Gas-liquid-solid Partitioning - Fine Mode (F5, Period I-III)

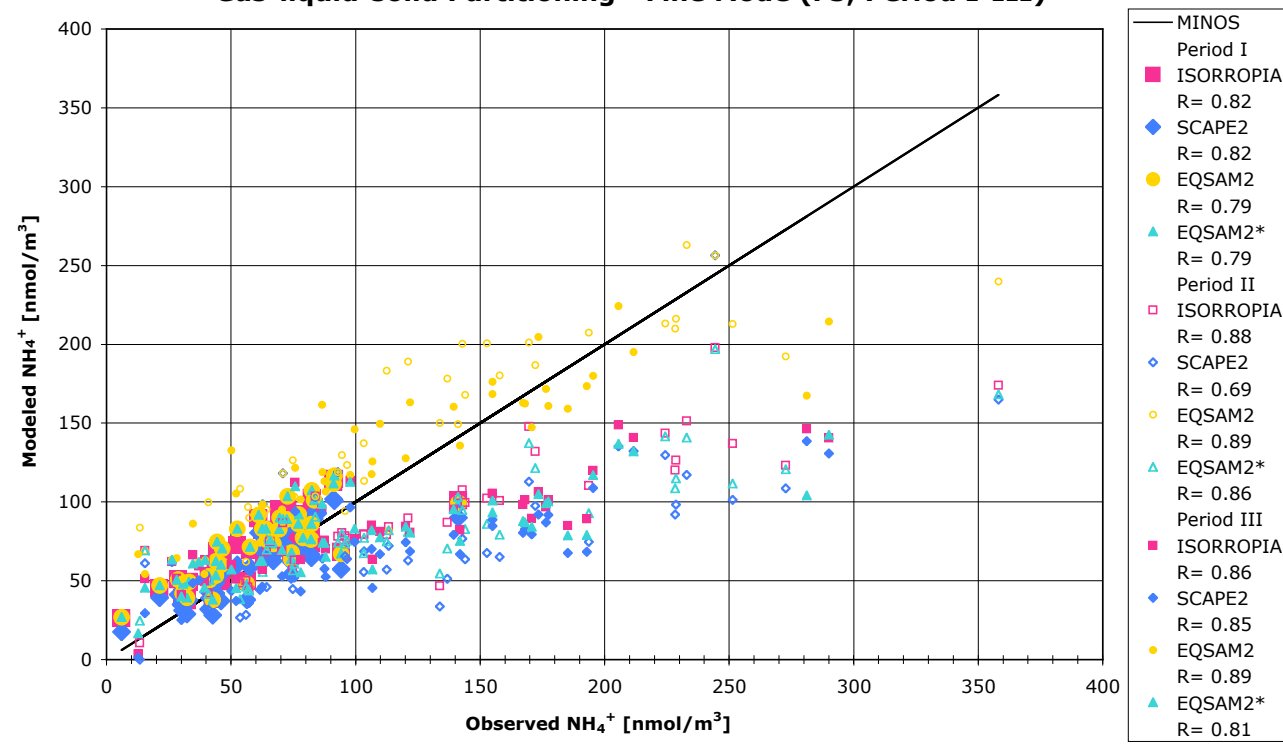

Fig. 7. Time series of measured (black solid line) and calculated fine mode aerosol ammonium (panel a) $\left[\mathrm{nmol} / \mathrm{m}^{3}\right.$ ] with the corresponding scatter plot (panel b) (model predictions versus observations) for the most comprehensive chemical system (F5/C5). The correlation coefficients (R) are given in the legends and the colors and symbols of the three models (ISORROPIA, SCAPE2, EQSAM2) are the same as in Fig. 6. The additional model EQSAM2* (turquoise, short-long-dotted dashed with closed triangles) is the same as EQSAM2 except for the input concentrations of mineral cations and lumped organic acids. See text for details. Note the different symbols for the scatter plot that indicate each period, i.e. large closed symbols are used for period I, small open symbols for period II and small closed symbols for period III. The symbols are the same as in panel (a). The correlation coefficients (R) are given in the legend of panel (b) for each period and model, while panel (a) shows the entire period (and each model). 
approach). In the subsequent application (forward approach) we account for the estimated amount of (lumped) organic acids that is needed to balance aerosol ammonium.

From this sensitivity study the following values of Lumped Organic Acids (LOA) in percentage of the total (estimated since unknown) particulate organic matter (POM) have been deduced for EQSAM2, while for EQSAM2* we used all of the measured LOA values, assuming that they explain for all three periods approximately $10 \%$ of POM:

I. Period (1 August 2001, 10:00 h-6 August 2001, 16:00 h):

- fine mode: $10 \%$ of POM as LOA

II. Period (6 August 2001, 16:00 h-12 August 2001, 19:00 h):

- fine mode: $70 \%$ of POM as LOA

III. Period (12 August 2001, 19:00 h-18 August 2001, 10:00 h):

- fine mode: $70 \%$ of POM as LOA

Note that for this modeling study we have assumed that the measured LOA (Fig. 4a), with values derived by Sciare et al. (2005), account for approximately $10 \%$ of the total though not measured particulate organic matter (POM), since POM might also include water soluble humic-like substances (HULIS). Thus, the total water soluble organic carbon fraction (WSOC) that was used as LOA input for EQSAM2 has been $70 \%$ of POM for period II and III instead of $10 \%$ that were used for EQSAM2* for all periods (accounting for all of the identified organic acids only).

The considerably larger amount of lumped organic acids, required to balance the observed fine mode ammonium during the two periods affected by biomass burning (i.e. period II and III), thus provides an indication of the fraction of additional organic matter, e.g. HULIS, which may be important in addition to the lumped organic acids considered. Assuming that the extracted organic acids are water soluble that roughly account for $10 \%$ of the total organic matter (as mentioned above), additionally $60 \%$ of the POM would be subject to neutralization by ammonium, which might be HULIS. This fraction would therefore behave as the WSOC fraction that consist of the low molecular weight (LMW) organic acids given in Sect. 2.

\section{Mineral cations (C5)}

Similarly to Fig. 7a, Fig. 8a shows the time series of measured nitrate concentrations (in $\mathrm{nmol} / \mathrm{m}^{3}$ ) for the aerosol coarse mode (chemical system C5), together with the model predictions by ISORROPIA, SCAPE2, EQSAM2, while Fig. 8b shows the associated scatter plots (model versus observations). In addition the results of EQSAM2* are shown. The asterisk (*) again denotes that EQSAM2 was constrained with different input concentrations (see below).
The time series for aerosol nitrate (Fig. 8a) show that the observed nitrate partitioning follows the $R H$ relatively well (compare with Fig. 3) for the coarse mode, in contrast to aerosol ammonium (Fig. 7a). Nitric acid partitions largely into the aerosol phase under humid conditions, which is less well captured by the models that include all additional mineral aerosol compounds (SCAPE2 and EQSAM2*). They largely overestimate coarse mode nitrate, especially for the dry period (II). In particular Figs. 8a and b show that - from all models that have been applied to the same input concentrations, i.e. ISORROPIA, SCAPE2, EQSAM2* - the model predictions of ISORROPIA are in best agreement with the observations for coarse mode nitrate, since mineral cations except $\left(\mathrm{Na}^{+}\right)$are neglected. And for the same reason, the model predictions of ISORROPIA differ most compared to the other model predictions for the dry period (II), which was influenced by Saharan dust. Only EQSAM2 yields a comparable close agreement with the observations (Fig. 8b) by considering all cations from sea salt and mineral dust. In contrast to EQSAM2, the predicted concentrations of coarse mode nitrate by EQSAM2* are closer to the predictions of SCAPE2 for the entire period and in particular for period II and III (Fig. 8).

Similar to the sensitivity of aerosol ammonium to the concentration of organic acids, aerosol nitrate appears to be quite sensitive to the overall concentration of mineral cations. In particular for the dry period (II), the additional cations from mineral dust leads to an overestimation of coarse mode nitrate compared to the observation.

This result indicates that not all of the measured mineral cations are required to neutralize the nitric acid to form nitrate. Similar to the required input concentration (threshold value) of the lumped organic acids, needed to balance the aerosol ammonium with respect to the observed concentration, the critical concentration of mineral cations has been determined to best match the observed nitrate concentration for each period by running EQSAM2 twice. In the first run the model is constrained by observed nitrate and nitric acid concentrations to predict the amount of mineral cations that are required to balance the model predictions for aerosol nitrate with the observations (reverse approach, first application). In the second application (forward approach) we then only account for the fraction of mineral cations that is needed to balance the anions. In this way we implicitly account for the unknown insoluble matter (cations), or the amount of cations not available to neutralize nitric acid due to long equilibration time-scales, or due to the possibility that nitric acid might just have been absorbed on the surface of mineral dust particles, still not being neutralized. From this sensitivity study the following values have been deduced for EQSAM2, while we used for EQSAM2*, consistently with all other EQMs and for all periods, the total concentration of measured cations according to Fig. 4b: 


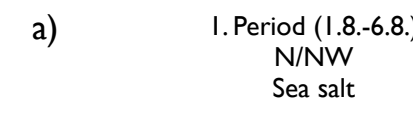

II. Period (6.8.-12.8.)

Subsidence

Dust + Biomass burning

III. Period (12.8.- I8.8.)

N/NE

Sea salt + Biomass burning

Aerosol Nitrate

Gas-liquid-solid Partitioning - Coarse Mode (C5)
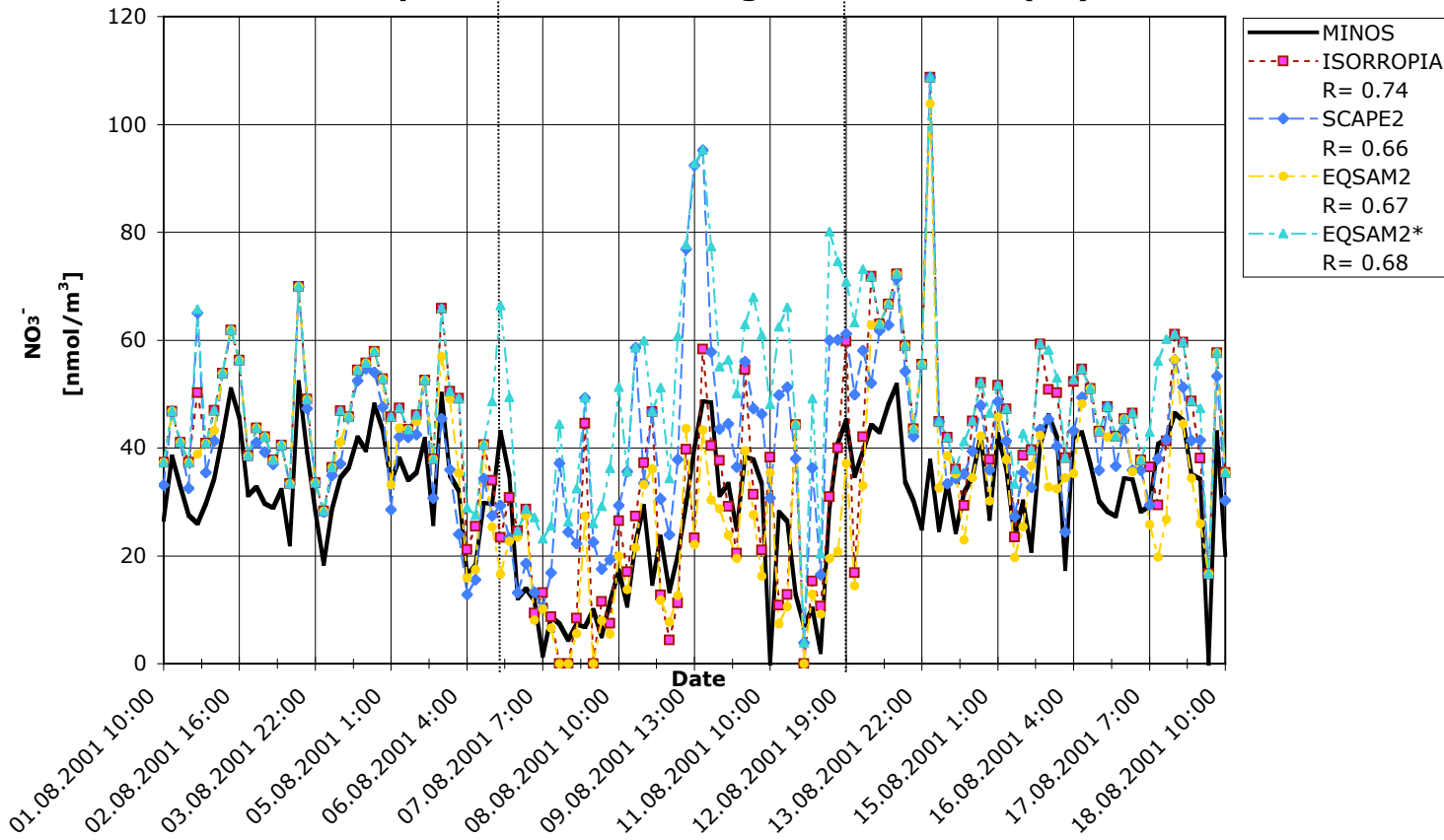

b)

Aerosol Nitrate

Gas-liquid-solid Partitioning - Coarse Mode (C5, Period I-III)

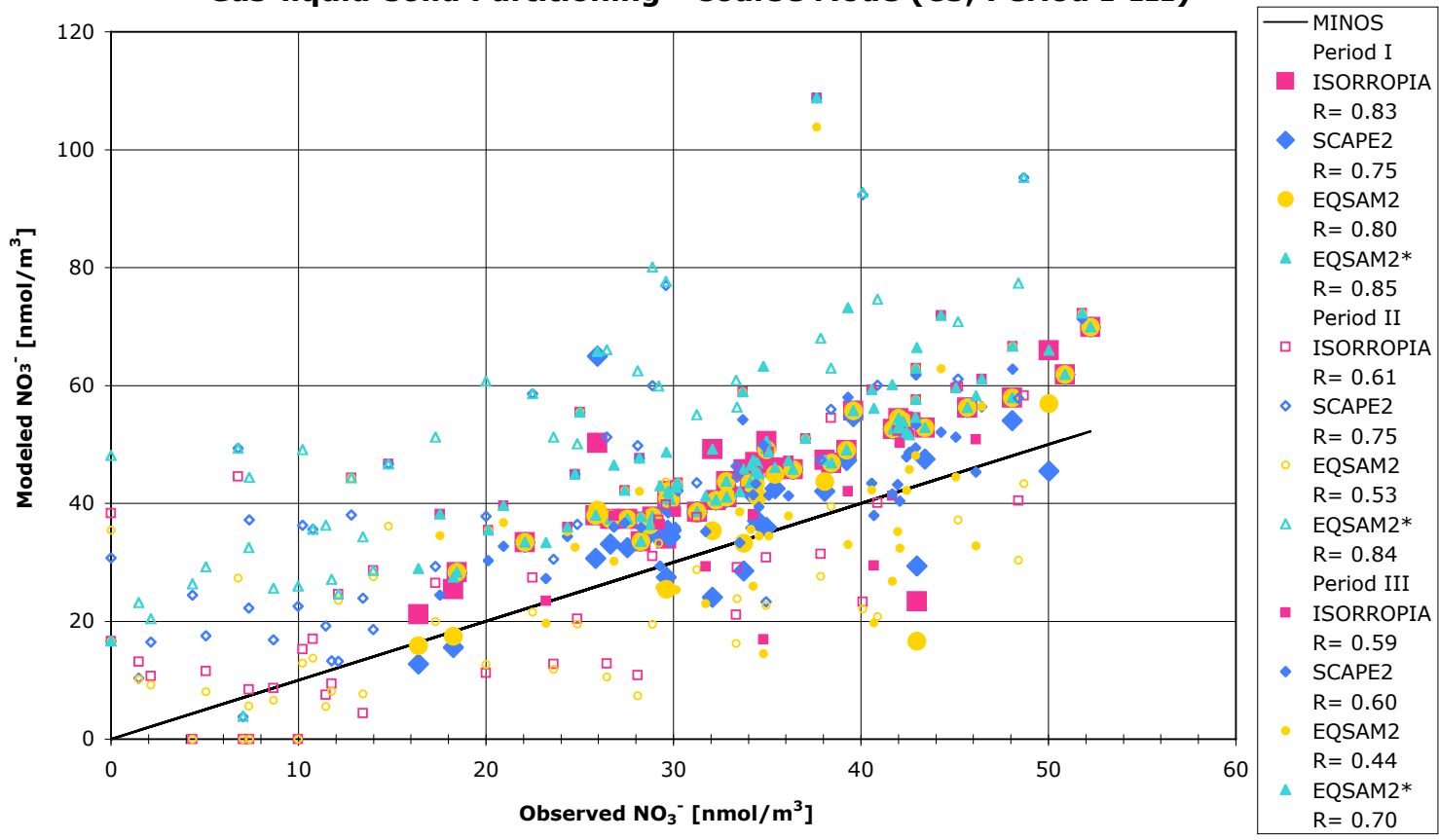

Fig. 8. Time series of measured (black solid line) and calculated coarse mode aerosol nitrate (panel a) $\left[\mathrm{nmol} / \mathrm{m}^{3}\right]$ and the corresponding scatter plot (panel b), analogous to Fig. 7. 
I. Period (1 August 2001, 10:00 h-6 August 2001, 16:00 h):

- coarse mode: $4 \%$ of POM as LOA, $60 \%$ of $\mathrm{Na}^{+}, 20 \%$ of $\mathrm{Ca}^{2+}$ and $\mathrm{Mg}^{2+}$

II. Period (6 August 2001, 16:00 h-12 August 2001, 19:00 h):

- coarse mode: $8 \%$ of POM as LOA, $60 \%$ of $\mathrm{Na}^{+}, 20 \%$ of $\mathrm{Ca}^{2+}$ and $\mathrm{Mg}^{2+}$

III. Period (12 August 2001, 19:00 h-18 August 2001, 10:00 h):

- coarse mode: $8 \%$ of POM as LOA, $60 \%$ of $\mathrm{Na}^{+}, 20 \%$ of $\mathrm{Ca}^{2+}$ and $\mathrm{Mg}^{2+}$

According to Fig. 4, aerosol nitrate is largely confined to the coarse mode, in contrast to ammonium that is mainly present in the fine mode. In particular the model results (Fig. 8b) are much closer to the observations for coarse mode nitrate for period I, with fewer discrepancies between the models compared to the results for period II and III, indicating that aerosol nitrate is mostly neutralized by sodium and less by other cations. The differences in the models predictions of EQSAM2 and EQSAM2* and the fact that the results of EQSAM2 are closer to the observations for period II and III compared to EQSAM2* (and the other EQMs) indicate that not all measured mineral cations were involved in the neutralization of nitric acid. Hence, the predictions of EQSAM2* are closer to SCAPE2 as both consider mineral cations, but both deviate most from the observations compared to EQSAM2 and ISORROPIA. This is in particular the case for the dry period, being strongly influenced by Saharan dust aerosols that lead to a significant contribution of mineral cations from mineral dust (in particular $\mathrm{Ca}^{2+}$ and $\mathrm{Mg}^{2+}$ ).

According to the results shown in Fig. 8, however, also not all measured sodium was needed for the neutralization of observed nitric acid during the two humid periods (I and III), which were predominantly influenced by coarse sea salt aerosol. The additional - although small - amount of nonsodium cations (in particular $\mathrm{Ca}^{2+}$ and $\mathrm{Mg}^{2+}$ ) lead to too high nitrate concentrations if all sodium is considered in the neutralization reactions, as the results of SCAPE2 and EQSAM2* indicate. Even for the case where we have neglected any additional mineral cations $\left(\mathrm{Ca}^{2+}, \mathrm{Mg}^{2+}\right.$ and $\left.\mathrm{K}^{+}\right)$ except sodium, the predicted nitrate concentrations are too high if all sodium is considered for the neutralization reactions, as indicated by the results of ISORROPIA. Obviously, not all sodium cations are required to neutralize nitric acid, even for the two humid periods (I and III). This indicates that for these cases sea salt particles might have consisted of an insoluble sodium chloride core, which did not equilibrate with nitric acid within the measurement interval of two-three hours. Approximately $40 \%$ of the sea salt particles (moles $\mathrm{m}^{-3}$ air) were not internally mixed but rather coated by nonneutralized nitric acid, possibly associated with an organic film.

\section{Discussion}

To study the temperature ( $\mathrm{T}$ ) and relative humidity $(R H)$ dependent gas/aerosol equilibrium partitioning of reactive nitrogen compounds of the observed $\mathrm{H}_{2} \mathrm{SO}_{4} / \mathrm{HSO}_{4}^{-} / \mathrm{SO}_{4}^{2-}-\mathrm{HNO}_{3} / \mathrm{NO}_{3}^{-}-\mathrm{NH}_{3} / \mathrm{NH}_{4}^{+}-\mathrm{HCl} / \mathrm{Cl}^{-}-$ $\mathrm{Na}^{+}-\mathrm{Ca}^{2+}-\mathrm{Mg}^{2+}-\mathrm{K}^{+}-\mathrm{H}_{2} \mathrm{O}$-system, including lumped organic acids (R-COOH) (Fig. 2), we have divided this complex aerosol system into five chemical systems for the fine (F1-F5) and coarse (C1-C5) aerosol mode, according to Table 1. This has been achieved by different constraints on the ionic composition, i.e. by subsequently including additional cations and anions. This distinction allowed a comparison of rather different EQMs (ISORROPIA, SCAPE2, EQSAM2) at the same and different levels of complexity.

While first of all our results show that all three EQMs yield comparable results (on average within $\sim 10 \%$ that approximately is the measurement uncertainty) if they are applied at the same level of complexity (involving chemical systems F1/C1-F3/C3 of Figs. 5 and $6 \mathrm{a}, \mathrm{c}$ ), the application of the EQMs at different levels of complexity (and the comparison with measurements) first of all indicates the importance of the consistent inclusion of (soluble) mineral cations and (lumped) organic acids. Note that the application of the three EQMs at the different levels of complexity is a much less well-constrained approach, which yields much less comparable results, especially under different chemical conditions, than applied at the same level of complexity (Fig. 5).

Note further that the so-called equivalent sodium approach (chemical system F3/C3, Table 1), should be regarded as an approximation only, because of inconsistencies in the RHDs. For instance, the RHD of $\mathrm{Na}_{2} \mathrm{SO}_{4}$ is $93 \%$ and higher than of $\mathrm{MgSO}_{4}$, which is $86 \%$, while the RHD of $\mathrm{NaHSO}_{4}$ is $52 \%$ and thus lower than that of $\mathrm{MgSO}_{4}$. In the case of the equivalent sodium approach, these differences in the RHDs will cause differences in the liquid/solid partitioning, which subsequently affects the gas-aerosol partitioning (also of nitrogen compounds). This picture becomes even more complicated as EQSAM2 and ISORROPIA consider deliquescence relative humidities of mixed salts (Nenes et al., 1998), since they are for thermodynamic reasons generally lower than the $R H D$ s of the individual salt compounds, which are only considered in SCAPE2 (Kim et al., 1995). Nevertheless, the models agree within $10 \%$ also for the equivalent sodium approach (F3/C3 of Fig. 5), which indicates that these differences are of secondary importance for the gas-aerosol partitioning of reactive nitrogen compounds. Obviously, it is more important to consistently include the major aerosol components, as demonstrated by the model comparison at different levels of complexity (F4/C4 and F5/C5) (Fig. 5).

Figures 5 and $6 \mathrm{~b}, \mathrm{~d}$ further reveal the relative importance of mineral cations and organic acids for the gas-aerosol partitioning of nitrogen compounds. For instance, our results show that (lumped) organic acids are required to correctly 
balance fine and coarse mode ammonium (Fig. 7). The reason is that ammonia is driven out of the aerosol phase if mineral cations are considered but not additional acids (e.g. organic acids), which is the case for ISORROPIA and SCAPE2 (Figs. 6a, c versus 6b, d). The situation becomes worse for the case of low sea salt concentrations and relatively high concentrations of cations from mineral (Saharan) dust (chemical system C5, Fig. 6d). However, for the two humid periods with high sea salt concentrations (period I and III) the coarse mode predictions of ISORROPIA compare relatively well, though for the wrong reason (as shown in Sect. 4.2.2).

Our results furthermore show that the consideration of major coarse mode mineral cations is important in order to balance aerosol nitrate as observed. For period I and III, the consideration of sodium from sea salt aerosol is most important. Accounting for all measured cations leads however to an overestimation of aerosol nitrate, in particular by SCAPE2 and EQSAM2* (Fig. 8). But even if only sodium is considered (as it is the case for ISORROPIA), aerosol nitrate is slightly overestimated. This indicates that most likely only a soluble fraction of mineral cations is in chemical and thermodynamic equilibrium with inorganic and organic acids. The fraction that did not neutralize the acids has most likely not been in equilibrium, i.e. insoluble coarse mode particles on which acids condensed without being neutralized - yielding externally rather than internally mixed aerosols. This fraction has been estimated by a sensitivity study to be approximately $80 \%$ for the measured calcium and magnesium (percentage in terms of moles per cubic meter air), by using the reverse option of EQSAM2 with running EQSAM2 twice (as described above). From this sensitivity study it also appeared that approximately $40 \%$ of the major mineral cation from sea salt $\left(\mathrm{Na}^{+}\right)$did not neutralize nitric acid. Only if we account for an insoluble fraction (deduced from the reverse approach), aerosol nitrate is balanced as observed. The fraction of nitric acid that remained un-neutralized is given by the difference of EQSAM2 and EQSAM2*. Since EQSAM2* is identical to EQSAM2, except that all measured mineral cations have been considered for the nitrate partitioning, EQSAM2* predicts for all periods consistently with SCAPE2 higher aerosol nitrate concentrations than EQSAM2.

Thus, the comparison of the EQMs at different levels of complexity indicates that the consistent accounting for inorganic and (lumped) organic acids together with (soluble) mineral cations and ammonium is probably most important in aerosol composition modeling studies, even if we can currently only realize this in a simplified way. Certainly, such a simplified approach is associated with uncertainties, e.g. lumping organic acids based only on the total of carboxylic groups and ignoring the possibility that part of the organic acids are semi-volatile (we have treated them as nonvolatile), or the fact that we have simplified the activity coefficient calculation by deriving the activity coefficients of semi-volatile compounds directly from $R H$ (Metzger et al. 2002a). Additional uncertainties arise from the use of filter measurements in particular for semi-volatile aerosol compounds such as ammonium nitrate, which was however not an important compound for this study (at least not during daytime), or the various assumptions made about the RHDs and the lack of knowledge on MRHD for mixed inorganic and organic salt solutions. Nevertheless, our simplified approach provides a first and apparently reasonably realistic evaluation of the gas-aerosol partitioning of reactive nitrogen compounds in the Mediterranean region.

\section{Conclusions}

We have used observational data from the MINOS measurement campaign in Crete, Greece (Fig. 1), to study the gasaerosol partitioning of reactive nitrogen compounds. A series of calculations has been performed using different thermodynamic aerosol composition models. We noticed that the gas-aerosol partitioning of reactive nitrogen compounds is rather complex as the Mediterranean lower atmosphere is influenced by varying periods with different levels of air pollution and distinct chemical aerosol composition. For instance, the core phase of the MINOS measurement campaign (1-18 August 2001) can be characterized by three different subperiods, i.e. basically two humid periods with high levels of sea salt aerosol interrupted by a dry period with high levels of mineral dust aerosol, while the two last periods were additionally influenced by biomass burning pollution (Fig. 3). The different levels of atmospheric aerosols and their ionic composition, and in particular the concentration levels of cations, can be used to characterize the different periods of air pollution. The results show that the concentration levels of cations are important for the gas-aerosol partitioning of reactive nitrogen compounds. The cations determine the neutralization level of acidic particles, which in turn determines the gas-aerosol partitioning of volatile or semi-volatile aerosol compounds, the hygroscopic growth, or the aerosol precursor gas concentration.

From the measurements (Fig. 4) it can readily be seen that the most important mineral cations are mainly present in the coarse mode, which indicates their natural origin, i.e. sodium from sea salt, and calcium, magnesium and a minor fraction of potassium from wind blown mineral dust (e.g. for period II from Saharan dust). In contrast, the major mineral cations present in the fine mode originated mainly from anthropogenic activities, i.e. ammonium and pyrogenic potassium. However, the main gaseous anthropogenic air pollutants, i.e. ammonia, nitric acid and organic acids, were as abundant as their natural counterparts and distributed over both the aerosol fine and coarse mode. For instance, the model applications (Figs. 5-8) confirmed that ammonia partitioned mainly into the fine mode, while nitric acid partitioned mainly into the coarse mode. This actually contradicts the assumption sometimes made that anthropogenic 
air pollutants are mainly confined to the aerosol fine mode, while natural air pollutants mainly occur in the coarse mode.

Our main conclusion is that it is essential to consistently include inorganic and (lumped) organic acids together with (soluble) mineral cations and ammonium in order to correctly predict the observed aerosol composition and the associated aerosol precursor gas concentrations. This result is consistent with the findings of Trebs et al. (2005) who came to the same conclusion, however, for a rather different air pollution regime, i.e. of biomass burning effluents over the tropical rainforest, investigated during the dry season of 2002 within the framework of LBA-SMOCC (Large-Scale Biosphere Atmosphere Experiment in Amazonia - Smoke Aerosols, Clouds, Rainfall, and Climate: Aerosols From Biomass Burning Perturb Global and Regional Climate).

\section{Appendix A}

In the following we briefly summarize the main new features of EQSAM2, a further development of EQSAM (Metzger, 2000; Metzger et al. 2002a, b). The main improvement is that EQSAM2 includes mineral cations $\left(\mathrm{Na}^{+}, \mathrm{Ca}^{2+}, \mathrm{Mg}^{2+}\right.$, $\mathrm{K}^{+}$) and lumped organic acids, as well as an extended description of the gas-liquid-solid partitioning by accounting for the various mineral salt compounds based on theoretically derived activity coefficients and single solute molalities. A detailed description and theoretical implications will be provided in a separate publication. The main new features applied in this study include:

- Gas/liquid/solid partitioning has been extended to include (lumped) organic acids, as well as major sea salt and crustal elements. The following system has been considered in this study: $\mathrm{H}_{2} \mathrm{SO}_{4} / \mathrm{HSO}_{4}^{-} / \mathrm{SO}_{4}^{2-}-\mathrm{HNO}_{3} / \mathrm{NO}_{3}^{-}-\mathrm{NH}_{3} / \mathrm{NH}_{4}^{+}-$ $\mathrm{HCl} / \mathrm{Cl}^{-}-\mathrm{Na}^{+}-\mathrm{Ca}^{2+}-\mathrm{Mg}^{2+}-\mathrm{K}^{+}-\mathrm{R}-\mathrm{COOH} / \mathrm{R}-$ $\mathrm{COO}^{-}-\mathrm{H}_{2} \mathrm{O}$-system.

- Extension of the stochiometric neutralization reactions to the above system; all reactions are based on cation/anion charge balance.

- Extended and improved single solute molalities for the above system.

- Water activities of single solutes and activities coefficients consistently calculated and derived from theory (based on Metzger et al., 2002a, and extended and generalized).

- Extended and improved water uptake for the above system, including temperature dependent relative humidities of deliquescence $(R H D)$ of all major salts of the above inorganic acids and cations, similar to SCAPE2 (Meng et al., 1995).
- Consideration of mutual relative humidities of deliquescence (MRHD), similar to ISORROPIA (Nenes et al., 1998).

- Differentiation between lumped low-molecular weight (LMW) polar organic acids, humic-like substances (HULIS) and un-identified particulate organic matter (POM) for the water uptake.

- The following dissociation equilibria:

$$
\begin{aligned}
\mathrm{NH}_{3}(\mathrm{~g}) & \Longleftrightarrow \mathrm{NH}_{4}^{+}(\mathrm{aq})+\mathrm{OH}^{-}(\mathrm{aq}) \\
\mathrm{HNO}_{3}(\mathrm{~g}) & \Longleftrightarrow \mathrm{H}^{+}(\mathrm{aq})+\mathrm{NO}_{3}^{-}(\mathrm{aq}) \\
\mathrm{HCl}(\mathrm{g}) & \Longleftrightarrow \mathrm{H}^{+}(\mathrm{aq})+\mathrm{Cl}^{-}(\mathrm{aq}) \\
\mathrm{HSO}_{4}^{-}(\mathrm{aq}) & \Longleftrightarrow \mathrm{H}^{+}(\mathrm{aq})+\mathrm{SO}_{4}^{2-}(\mathrm{aq})
\end{aligned}
$$

giving rise to e.g. aerosol nitrate formation at high relative humidity $(R H)$ for the sulfate "rich" and "very rich" cases (domain 3 and 4), consistent with the other EQMs (ISORROPIA and SCAPE2).

- $\mathrm{pH}$ calculation including $\mathrm{OH}^{-}(\mathrm{aq})$ and $\mathrm{H}^{+}(\mathrm{aq})$ from the dissociation of $\mathrm{HSO}_{4}^{-}$, and the uptake of $\mathrm{NH}_{3}, \mathrm{HNO}_{3}$, and $\mathrm{HCl}$ in aqueous solutions.

- Dependency of the $\mathrm{NH}_{4} \mathrm{NO}_{3}$ equilibrium constant on the ionic strength fraction (Y) according to Stelson and Seinfeld (1982).

- Full analytical solution of the gas/aerosol equilibrium partitioning.

- Vectorized and re-structured code.

- Several new switches:

- To account for the reverse modus, i.e. predict gas phase species from aerosol concentrations. Default is forward modus, i.e. gas-aerosol partitioning is calculated from the sum of total gas and aerosol concentrations.

- To account for uptake (and dissociation) of $\mathrm{NH}_{3}(\mathrm{~g})$, $\mathrm{HNO}_{3}(\mathrm{~g}), \mathrm{HCl}(\mathrm{g})$ on wet and/or acid aerosol particles.

- To account for the $\mathrm{NH}_{4} \mathrm{NO}_{3}$ ionic strength fraction Y.

- To force aerosol particles to be dry (no aerosol water).

- To force liquids (supersaturated solutions).

- To account for the coexistence of liquids and solids.

- To account for hysteresis effects (includes gas/liquid/solid partitioning but requires history of the aerosol water content).

- To account for individual aerosol components. 
Acknowledgements. This work was partly financed through the European Union projects PHOENICS (http://phoenics.chemistry.uoc.gr, EVK2-CT-2001-00098) and ANTISTORM (http://antistorm.isac.cnr.it, NEST-12444). We thank C. Oikonomou for the IC measurements and J. Sciare for providing the organic acid values and size-segregated anions and cations. N. Mihalopoulos thanks the Ministry of Education through Pythagoras II project for financial support.

Edited by: F. J. Dentener

\section{References}

Bardouki, H., Liakakou, H., Economou, C., Sciare, J., Smolík, J., Ždímal, V., Eleftheriadis, K., Lazaridis, M., and Mihalopoulos, N.: Chemical composition of size resolved atmospheric aerosols in the eastern Mediterranean during summer and winter, Atmos. Environ., 37, 195-208, 2003.

Berresheim, H., Plass-Dülmer, C., Elste, T., Mihalopoulos, N., and Rohrer, F.: $\mathrm{OH}$ in the coastal boundary layer of Crete during MINOS: Measurements and relationship with ozone photolysis, Atmos. Chem. Phys., 3, 639-649, 2003,

http://www.atmos-chem-phys.net/3/639/2003/.

Cofer, W. R., Collins, V. G., and Talbot, R.: Improved aqueous scrubber for collection of soluble atmospheric trace gases, Environ. Sci. Technol., 19, 557-560, 1985.

Kawamura, K., Kasukabe, H., and Barrie, L.: Source and reaction pathways of dicarboxylic acids, ketoacids and dicarbonyls in Arctic aerosols: One year of observations, Atmos. Environ., 30, 1709-1722, 1996.

Kawamura, K. and Sakaguchi, F.: Molecular distributions of water soluble dicarboxylic acids in marine aerosols over the Pacific Ocean including tropics, J. Geophys. Res., 104, 3501-3509, 1999.

Kim, Y. P. and Seinfeld, J. H.: Atmospheric gas/aerosol equilibrium III. Thermodynamics of crustal elements $\mathrm{Ca} 2+, \mathrm{K}+$, and $\mathrm{Mg} 2+$, Aerosol Sci. Technol., 22, 93-110, 1995.

Kouvarakis, G. and Mihalopoulos, N.: Seasonal variation of dimethylsulfide in the gas phase and of methanesulfonate and non-sea-salt sulfate in the aerosol phase measured in the Eastern Mediterranean atmosphere, Atmos. Environ., 36, 929-938, 2002.

Kouvarakis, G., Doukelis, Y., Mihalopoulos, N., Rapsomanikis, S., Sciare, J., and Blumthaler, M.: Chemical, physical and optical characterization of aerosol during PAUR II experiment, J. Geophys. Res., 107, 814, doi:10.1029/2000JD000291, 2002.

Krivacsy, Z., Hoffer, A., Sarvari, Z., Temesi, D., Baltensperger, U., Nyeki, S., Weingartner, E., Kleefeld, S., and Jennings, S. G.: Role of organic and black carbon in the chemical composition of atmospheric aerosol at European background sites, Atmos. Environ., 35, 6231-6244, 2001.

Lelieveld, J., Berresheim, H., Borrmann, S., Crutzen, P. J., Dentener, F. J., Fischer, H., Feichter, J., Flatau, P. J., Heland, J., Holzinger, R., Korrmann, R., Lawrence, M. G., Levin, Z., Markowicz, K. M., Mihalopoulos, N., Minikin, A., Ramanathan, V., de Reus, M., Roelofs, G. J., Scheeren, H. A., Sciare, J., Schlager, H., Schultz, M., Siegmund, P., Steil, B., Stephanou, E. G., Stier, P., Traub, M., Warneke, C., Williams, J., and Ziereis,
H.: Global Air Pollution Crossroads over the Mediterranean, Science, 298, 794-799, 2002.

Meng, Z., Seinfeld, J. H., Saxena, P., and Kim, Y. P.: Atmospheric gas/aerosol equilibrium. IV: Thermodynamics of carbonates, Aerosol Sci. Technol., 131-154, 1995.

Meng, Z. and Seinfeld, J. H.: Time scales to achieve atmospheric gas/aerosol equilibrium for volatile species, Atmos. Environ., 30, 2889-2900, 1996.

Metzger, S. M.: Gas/Aerosol Partitioning: A simplified Method for Global Modeling, Ph.D. Thesis, University Utrecht, The Netherlands, ISBN:90-393-2510-3, http://www.library.uu. nl/digiarchief/dip/diss/1930853/inhoud.htm/, 2000.

Metzger, S. M., Dentener, F. J., Lelieveld, J., and Pandis, S. N.: Gas/aerosol partitioning I: a computationally efficient model, J Geophys. Res., 107, D16, doi:10.1029/2001JD001102, 2002a.

Metzger, S. M., Dentener, F. J., Jeuken, A., Krol, M., and Lelieveld, J.: Gas/aerosol partitioning II: global modeling results, J Geophys. Res., 107, D16, doi:10.1029/2001JD001103, 2002b.

Moya, M., Ansari, A. S., and Pandis, S. N.: Partitioning of nitrate and ammonium between the gas and particulate phases during the 1997 IMADA-AVER study in Mexico City, Atmos. Environ., 35, 1791-1804, 2001.

Nenes A., Pilinis, C., and Pandis, S. N.: Isorropia: A new thermodynamic model for multiphase multicomponent inorganic aerosols, Aquatic Geochemistry, 4, 123-152, 1998.

Salisbury, G., Williams, J., Holzinger, R., Gros, V., Mihalopoulos, N., Vrekoussis, M., Sarda-Estève, R., Berresheim, H., von Kuhlmann, R., Lawrence, M., and Lelieveld, J.: Ground-based PTR-MS measurements of reactive organic compounds during the MINOS campaign in Crete, July-August 2001, Atmos. Chem. Phys., 3, 925-940, 2003

Schaap, M., Müller, K., and ten Brink, H. M.: Constructing the European aerosol nitrate concentration field from quality analysed data, Atmos. Environ., 36(8), 1323-1335, 2002.

Sciare, J. and Mihalopoulos, N.: A new technique for sampling and analysis of atmospheric dimethylsulfoxide (DMSO), Atmos. Environ., 34, 151-156, 2000.

Sciare, J., Bardouki, H., Moulin, C., and Mihalopoulos, N.: Aerosol sources and their contribution to the chemical composition of aerosols in the Eastern Mediterranean Sea during summertime, Atmos. Chem. Phys., 3, 1-12, 2003 a.

Sciare, J., Cachier, H., Oikonomou, K., Ausset, P., Sarda-Estève, R., and Mihalopoulos, N.: Characterization of Carbonaceous Aerosols during the MINOS campaign in Crete, July-August 2001: a multi-analytical approach, Atmos. Chem. Phys., 3, 1743-1757, 2003b.

Sciare, J., Oikonomou, K., Cachier, H., Mihalopoulos, N., Andreae, M. O., Maenhaut, W., and Sarda-Estève, R.: Aerosol mass closure and reconstruction of the light scattering coefficient over the Eastern Mediterranean Sea during the MINOS campaign, Atmos. Chem. Phys., 5, 2253-2265, 2005,

http://www.atmos-chem-phys.net/5/2253/2005/.

Stelson, A. W. and Seinfeld, J. H.: Thermodynamic Prediction of the Water Activity, $\mathrm{NH}_{4} \mathrm{NO}_{3}$ Dissociation-Constant, Density and Refractive-Index for the $\mathrm{NH}_{4} \mathrm{NO}_{3}-\left(\mathrm{NH}_{4}\right)_{2} \mathrm{SO}_{4}-\mathrm{H}_{2} \mathrm{O}$ System at $25^{\circ} \mathrm{C}$, Atmos. Environ., 16(10), 2507-2514, 1982.

Traub, M., Fischer, H., de Reus, M., Kormann, R., Heland, J., Ziereis, H., Schlager, H., Holzinger, R., Williams, J., Warneke, C., de Gouw, J., and Lelieveld, J.: Chemical characteristics as- 
signed to trajectory clusters during the MINOS campaign, Atmos. Chem. Phys., 3, 459-468, 2003,

http://www.atmos-chem-phys.net/3/459/2003/.

Trebs, I., Metzger, S., Meixner, F. X., Helas, G., Hoffer, A., Andreae, M. O., Moura, M. A. L., da Silva Jr., R. S., Slanina, J., Rudich, Y., Falkovich, A., and Artaxo, P.: The $\mathrm{NH}_{4}^{+}-\mathrm{NO}_{3}^{-}-\mathrm{Cl}^{-}-$ $\mathrm{SO}_{4}^{2-}-\mathrm{H}_{2} \mathrm{O}$ system and its gas phase precursors at a rural site in the Amazon Basin: How relevant are crustal species and soluble organic compounds?, J Geophys. Res.-Atmos., 110, D07303, doi:10.1029/2004JD005478, 2005.
Wexler, A. S. and Seinfeld, J. H.: The distribution of ammonium salts among a size and composition dispersed aerosol, Atmos. Environ., 24A, 1231-1246, 1990. 